\title{
WestVirginiaUniversity
}

THE RESEARCH REPOSITORY @ WVU

Graduate Theses, Dissertations, and Problem Reports

2009

\section{Application and evaluation of spiral separators for fine coal cleaning}

Zhuping Che

West Virginia University

Follow this and additional works at: https://researchrepository.wvu.edu/etd

\section{Recommended Citation}

Che, Zhuping, "Application and evaluation of spiral separators for fine coal cleaning" (2009). Graduate Theses, Dissertations, and Problem Reports. 2064.

https://researchrepository.wvu.edu/etd/2064

This Thesis is protected by copyright and/or related rights. It has been brought to you by the The Research Repository @ WVU with permission from the rights-holder(s). You are free to use this Thesis in any way that is permitted by the copyright and related rights legislation that applies to your use. For other uses you must obtain permission from the rights-holder(s) directly, unless additional rights are indicated by a Creative Commons license in the record and/ or on the work itself. This Thesis has been accepted for inclusion in WVU Graduate Theses, Dissertations, and Problem Reports collection by an authorized administrator of The Research Repository @ WVU. For more information, please contact researchrepository@mail.wvu.edu. 


\title{
Application and Evaluation of Spiral Separators for Fine Coal Cleaning
}

\author{
Zhuping Che \\ Thesis Submitted to the \\ College of Engineering and Mineral Resources \\ at West Virginia University \\ in Partial Fulfillment of the Requirements \\ for the degree of \\ Master of Science \\ in \\ Mining Engineering
}

Felicia F. Peng, PhD.

Syd S. Peng, PhD.

Yi Luo, PhD

Department of Mining Engineering

Morgantown, West Virginia

2009

Keywords: Fine Spiral; Clean Coal; Middings; Refuse; Sepcific Gravity Seperation 


\section{Abstract \\ Application and Evaluation of Spiral Separators for Fine Coal Cleaning}

\section{Zhuping Che}

Eight buckets of wet coal samples were collected from Shade Coal Preparation Plant, including the feed, clean coal, refuse, and middlings for fine spiral and coarse spiral, respectively. Float-sink analysis was performed on these size intervals using LMT (Lithium Metatungstate) liquids. Size distribution analysis is conducted for each size fraction of the above eight samples to evaluation the effectiveness of spiral separation. Wet sieving method was used for size distribution analysis.

From the tests, the following conclusion can be drawn: 1) The fine spiral is able to recovery $65.5 \%$ of the deslime hydrocyclone underflow as clean coal with an ash content of $8.26 \%$. 2) The ash contents for the refuse and middlings from the fine spiral are almost the same, which could be caused by the improper position of splitter. 3) The coarse spiral recovers $61.5 \%$ of the 15 -inch hydrocyclone underflow as clean coal with an ash content of $7.26 \%$. 4) For the coarse spiral, the misplacement of mineral contents to the clean coal is not significant as opposed to fine spiral. There are various degrees of misplacement of clean coal to the refuse of the coarse spiral.

Based on the conclusions above, the following recommendations are made: 1) For the fine spiral, the middlings should be mixed with the refuse, instead of mixing with clean coal as final product. The position of splitter between the middlings and the refuse should be adjusted towards the outer rim of the spiral to reduce the ash content in the middlings. 2) For the coarse spiral, the middlings should be combined with clean coal to obtain combined clean coal with satisfactory ash content. If low ash content is desired, the position of splitter between middlings and the refuse can be adjusted towards the outer rim. 


\section{Table of Contents}

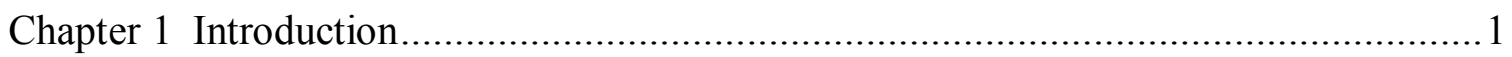

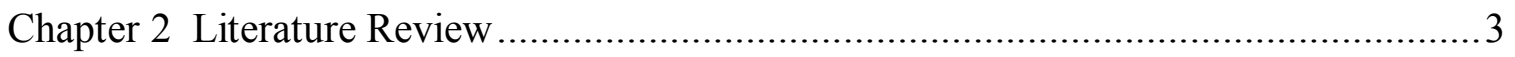

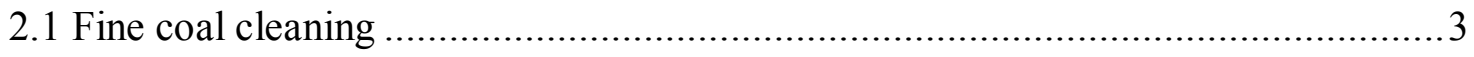

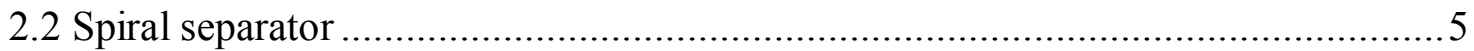

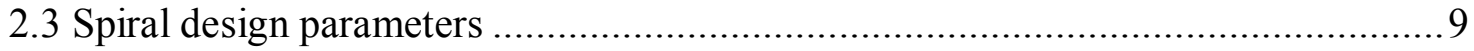

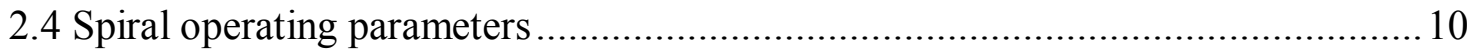

2.5 Advantage and disadvantage of spiral separators ............................................... 12

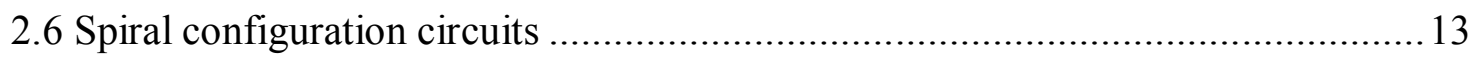

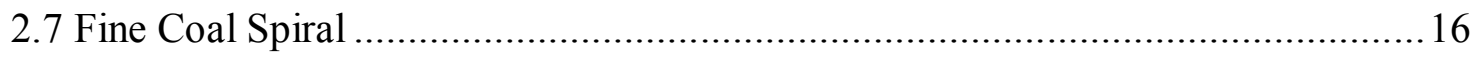

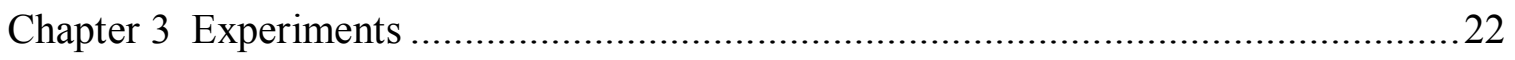

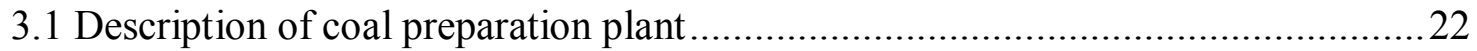

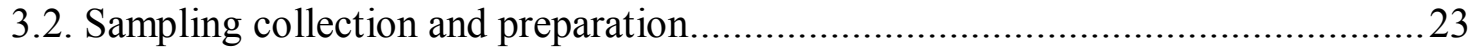

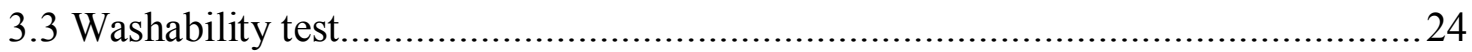

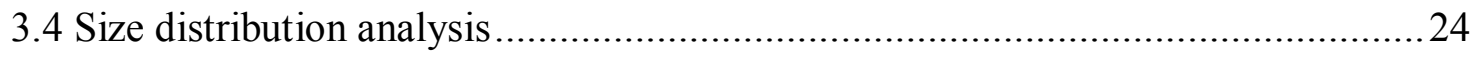

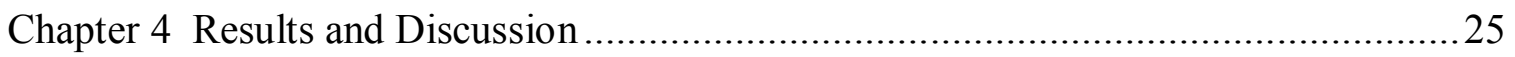

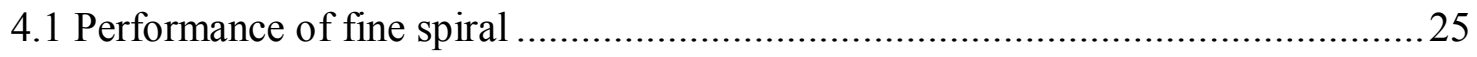

4.1.1 Products of fine coal spiral ...........................................................................2

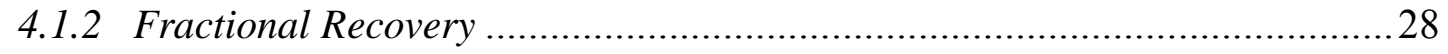

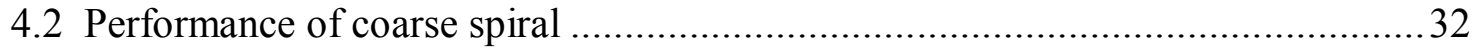

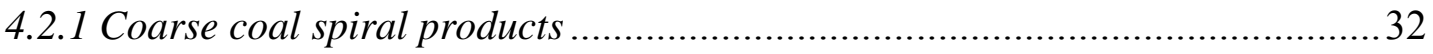

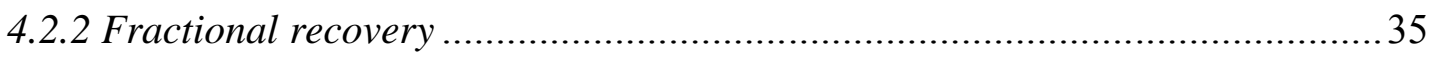

4.3 Predicted Model for Fine and Coarse Spirals ....................................................... 39

Chapter 5 Conclusions and Recommendations.......................................................... 44 


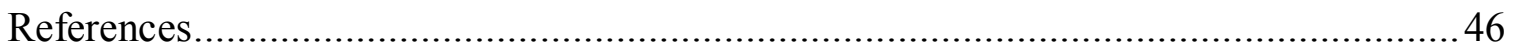

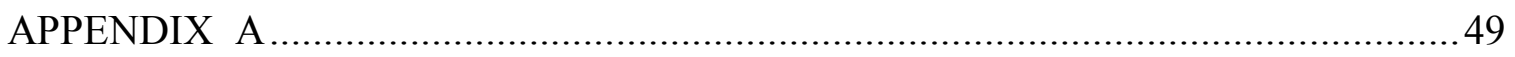

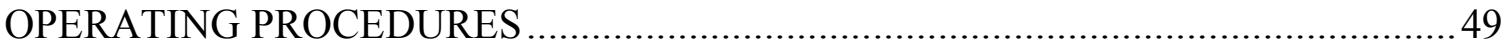

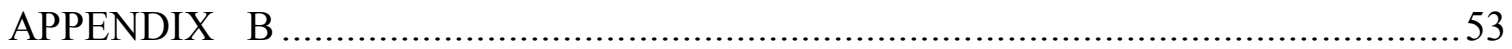

DESLIMED BITUMINOUS COAL TEST RESULTS .............................................53 


\section{List of Figures}

Figure 2.1 Coal spiral separation fundaments (Weldon, 1997) .................................. 8

Figure 2.2 Cross-section of a spiral trough flow (Matthews et al., 1999)..................... 8

Figure 2.3 General Arrangement of a Duplex Compound Spiral (MacNamara et.al. 1996).

Figure 2.4 Feed rate versus cut-point of a spiral separation (Mikhail et al., 1988;

Kohmuench, 2000). 12

Figure 2.5 Circuit configurations of spiral separation for fine coal (Luttrell, 2003)....... 14

Figure 2.6 The SX7 spiral by Multotec Process Equipment Ltd of Spartan ................. 18

Figure 3.1 Spiral separation flowsheet at Shade Coal Preparation Plant ......................23

Figure 4.1 Direct ash content for fine spiral by specific gravity interval...................27

Figure 4.2 Direct weight percent for fine spiral by specific gravity interval...............28

Figure 4.3 Distribution Curve for Fine Spiral (Size Distribution: $+0.210 \mathrm{~mm})$........... 29

Figure 4.4 Distribution Curve for Fine Spiral (Size Distribution: $-0.210 \mathrm{~mm}+0.149 \mathrm{~mm}$ ).

Figure 4.5 Distribution Curve for Fine Spiral (Size Distribution: -0.149mm+0.074mm). 30

Figure 4.6 Distribution Curve for Fine Spiral (Size Distribution: -0.074mm+0.044mm).

Figure 4.7 Distribution Curve for Fine Spiral (Size Distribution: $-0.044 \mathrm{~mm}$ ). .............31

Figure 4.8 Distribution Curve for fine spiral coal (composite) ............................... 32

Figure 4.9 Direct weight percent for coarse spiral by specific gravity interval..............34

Figure 4.10 Direct ash percent for coarse spiral by specific gravity interval. ..............35

Figure 4.11 Distribution Curve for Coarse Spiral (Size Distribution: $+1.190 \mathrm{~mm}$ ). ....... 36

Figure 4.12 Distribution Curve for Coarse Spiral ............................................. 37

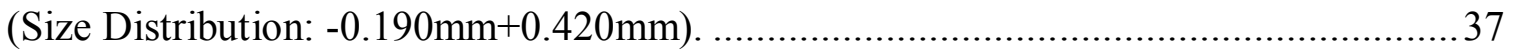


Figure 4.13 Distribution Curve for Coarse Spiral.................................................... 37

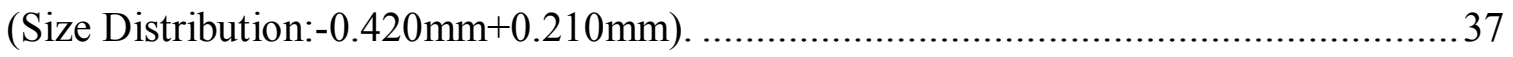

Figure 4.14 Distribution Curve for Coarse Spiral .................................................... 38

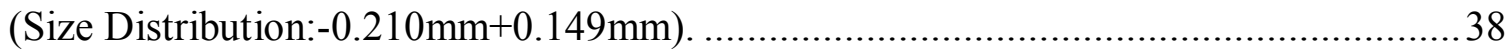

Figure 4.15 Distribution Curve for Coarse Spiral (Size ........................................... 39

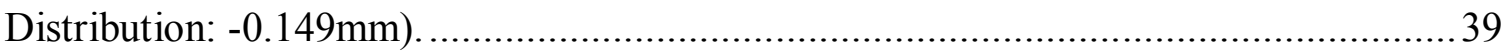

Figure 4.17 Distribution curves compared between the experiments data and methemetic model for Coarse Spiral (Composite Size Distribution)............................................. 41 


\section{List of Tables}

Table 1.1 Design parameters of spiral separator................................................

Table 2.2 Operation parameters of spiral separators............................................. 11

Table 2.3 Industrial comparison of different spiral circuit configurations................... 15

Table 4.1 Summary of the performance of fine spiral......................................... 26

Table 4.2 Summary of the performance of coarse spiral. .......................................33

Table 4.3 Summary of the fine and coarse spiral parameters................................. 43 


\section{Acknowledgements}

I would like to thank Dr. F.F.Peng for her patience and guidance during my time at Mining Engineering in WVU. I am grateful for the time and energy she invested in me.

I would like to thank Dr. Syd. Peng and Dr. Yi Luo for advising and guidance during my graduate study.

I would like to thank my parents and my families for their love and supports. 


\section{Chapter1}

\section{Introduction}

It has been recognized that coal preparation plays an important role in improving the quality of coal, producing a saleable product to meet the energy demand at a reasonable cost, and mitigating the environmental impact of energy production, including reduced emissions of $\mathrm{SO}_{2}, \mathrm{CO}_{2}$, and particulates. Recent energy price leap and strong energy demand worldwide have led to an increasing interest in the research and development of coal preparation technology to recover fine coal $(<3 \mathrm{~mm})$, especially the fine fraction of $<$ $1 \mathrm{~mm}$.

Spiral separator is one of the most effective devices for cleaning fine coals $(<1 \mathrm{~mm})$, with the following advantages: low cost, high separation efficiency, and ease of operation (MacHunter et. al., 2003; Weldon, 1997). The shortcomings of spiral separators include relatively high specific gravity cut-points, relatively low unit throughput, the need for multi-stage processing, and limited acceptable feed size range (MacHunter et. al., 2003; Kohmuench, 2000). In particular, the specific gravity (SG) cut-points of spiral separators $(>1.7 \mathrm{SG})$ are much higher than those of the dense medium vessels for coarse coal, which could result in either a loss of clean coal in tailings or a decrease in clean coal quality (DTI, 2001). To address this advantage, spirals are often employed in multi-stage circuits where the clean coal and/or middling streams from primary spirals are re-suspended and reprocessed in secondary spirals. The secondary middling can be (a) discarded with tailings (loss of yield), (b) retained as a product (sacrifice of quality), or (c) recycled back to the feed of rougher spirals. 
Spiral separators are employed in Shade Coal Preparation Plant, PBS Coals, Inc., near Central City, Pennsylvania, to recover fine coal. The Plant processes run-of-mine coal at a rate of $600 \mathrm{TPH}$, producing about 2,500 tons of clean coal per shift. Besides spirals, the preparation plant flow sheet consists of a heavy medium vessel, heavy medium cyclone, and hydro cyclone. Two sets of spirals are installed with one processing the underflow of 15 -inch hydro cyclones (particle size $<1.0 \mathrm{~mm}$ ) and the other cleaning the underflow of 10 -inch hydro cyclones (particle size $<0.37 \mathrm{~mm}$ ).

The objective of this study is to evaluate the effectiveness of the spiral separators in cleaning fine coal with different size ranges $(<1.0 \mathrm{~mm}$ and $<0.37 \mathrm{~mm})$, and to provide recommendations for performance improvement. 


\section{Chapter 2}

\section{Literature Review}

\subsection{Fine coal cleaning}

The processes used in coal preparation are largely determined by the variability in size of the feed coal and the size range desired in the final products. Coal preparation methods are often categorized by the coal size range: coarse coal, small coal, fine coal, and ultrafine coal. Although there are some overlap among the principal methods and their corresponding equipment for coal cleaning, the following size ranges are commonly accepted (DTI, 2001):

- Coarse coal: $>25 \mathrm{~mm}$

- Small coal: $25-3 \mathrm{~mm}$

- Fine coal: $<3 \mathrm{~mm}$

- Ultrafine coal: $<0.15 \mathrm{~mm}$

In general, dense medium (DM) separation (DM vessels or DM cyclones) can efficiently clean coarse coal and small coal to obtain products with a good quality. For fine coal, there has been a long debate among coal producers throughout the world regarding the pros and cons of fine coal treatment and recovery. In the past, common practice of discard of fines directly to lagoons or slurry ponds was justified due to the cost of fines recovery, increased difficulty in product handling (such as dewatering), and lack of efficient separation equipment. The current trend for processing fine coals has been shifted towards recovery maximization, which favors fine coal recovery, due to the 
increase energy price, the decreasing energy reserve (including coal, oil and natural gas), and technology improvement. Currently, several processes are available for fine coal cleaning to meet the requirements for sufficient utilization of natural resources and a growing emphasis on coal product quality.

For fine coal with a size range of $<0.6 \mathrm{~mm}$, froth flotation is the most commonly used process for coal preparation (Honaker and Mohanty, 1996). The major development in recent years in mechanical flotation cells is the increase in cell size and treatment capacity, and the maximum size of flotation cell is close to $40 \mathrm{~m}^{3}$ per cell (DTI, 2001). Along with the development of large flotation cell, other selective flotation technologies, such as column flotation, are developed and become popular. It is believed that the elimination of mechanical agitation and addition of spray water significantly increase the selectively of column flotation.

For fine coal of $3.0-0.1 \mathrm{~mm}$, spiral separators, along with teeter-bed separators are most appropriate choices in coal preparation plants. A teeter-bed separator consist of an open top cell and elutriation water is introduced through a series of distribution pipes evenly spaces across the base of the cell (Kohmuench et al., 2006). Feed is injected into the upper portion of the cell. The settling particles encounter the upward flow of elutriation water, creating a fluidized teeter-bed of suspended particles. The small or light particles concentrate in the upper portion of the separator and are eventually carried over the top of the vessel into a clean coal launder, while the large or heavy particles settle to the bottom and are discharged.

For ultrafine coal, conventional gravity concentration techniques are not very effective. Recent research and development has focused on the enhanced density 
separators or enhanced froth flotation for ultrafine coal cleaning. So far, there are no proved processes in handling ultrafine coal and research is much-needed in this area.

\subsection{Spiral separator}

Spiral separator is one of the most flexible gravity concentration devices commonly used in mineral processing industry worldwide. Spiral separators were developed by Humphreys in the early 1940s for concentration of heavy minerals, and were first used for fine coal cleaning in the US in 1947 (Kohmuench, 2000; Mikhail et al., 1988). Spirals were also used in Western Canada in the 1950s. Early spirals were constructed by using either cast iron or cast concrete with only one start per unit, leading to the large area requirement. The modern spirals were developed in Australia in the early 1980s by using a composite structure of glass fiber enforced plastic lined with wear-resistant polyurethane (Weldon, 1997). This technique guaranteed the replication of the exact separating surface, enhancing the separation efficiency and the consistency of product quality.

Efforts were made to standardize the required number of turns needed on a spiral separator for different ores. Early Australia industry utilized spirals with as few as 2 turns for coal separation. A 5 to 6 turn spirals were recommended to achieve optimum fine coal separations. Modern spirals can have as many as 7 turns to achieve the required separation performance (Holland-Bratt, 1995). Spirals are generally perceived as a gravity concentrator for cleaning fine coal in the size range of $0.1 \mathrm{~mm}$ to $2-3 \mathrm{~mm}$ (Burt 1984; Palowitch et al., 1991, Kapur and Meloy, 1998). Recent product experience and research efforts indicate that spirals are one of the most effective methods for cleaning 
the fine coal with a size range from $1 \mathrm{~mm}$ to $0.1 \mathrm{~mm}$ (Luttrell, 2003; Bethell and Arnold, 2003).

The simple structure of spiral separators consists of an open trough which twists downwards in helix configuration around a vertical axis in the center (Wills, 1992; Figure 1). Slurry is fed to the top of the separator and separation takes place radically based on the density and size of different mineral particles under a combination of difference forces, i.e., gravity force, centrifugal force, drag force, lift force, and friction force (Kapur and Meloy, 1998;). The separation mechanism in spiral separation is the combined effect of various forces applied to the particles in the slurry. Some of the forces acting on a particle can be mathematically presented as follows (Mikhail, et al., 1988; Equation 1, Radial forces; Equation 2, tangential forces).

$$
\begin{aligned}
& \frac{\pi D^{3}}{6}\left(\sigma_{p} \frac{U_{p}^{2}}{R}-\sigma_{l} \times \frac{U_{l}^{2}}{R}\right)-\left(F_{r s}-F_{r}\right)=\frac{\pi D^{3}}{6} \sigma_{p} \alpha_{r} \\
& \frac{\pi D^{3}}{6}\left(\sigma_{p}-\sigma_{l}\right) g \cos \psi-\left(F_{t s}+F_{r}\right)=\frac{\pi D^{3}}{6} \sigma_{p} \alpha_{t}
\end{aligned}
$$

Where, $\mathrm{D}=$ particle diameter

$$
\begin{aligned}
& \sigma_{p}=\text { particle density } \\
& \sigma_{\mathrm{l}}=\text { carrier liquid density } \\
& \mathrm{g}=\text { gravitational acceleration } \\
& \mathrm{R}_{\mathrm{p}}=\mathrm{R}_{\mathrm{l}}=\mathrm{R}=\text { particle, carrier liquid radius of curvature } \\
& \mathrm{U}_{\mathrm{p}}=\text { particle velocity at ' } \mathrm{p} \text { ' } \\
& \mathrm{U}_{\mathrm{l}}=\text { carrier liquid velocity at ' } \mathrm{p} \text { ' } \\
& E_{r s}, F_{r}=\text { tangential and radical shear reaction force }
\end{aligned}
$$




$$
\begin{aligned}
& F_{t z}, F_{r}=\text { tangential and radial frictional drag forces } \\
& \psi=\text { angle between the tangential direction and the vertical } \\
& \alpha_{r}, \alpha_{t}=\text { radial and tangential accelerations respective of the particle }
\end{aligned}
$$

The first term on the left side in Eq. (1) is the centrifugal force counteracted by the pressure gradient in the moving fluid, and the fist term on the left side in Eq. (2) is the gravitational force component counteracted by the buoyancy force component in the tangential direction.

The net effect of the forces and the rising and falling currents in the slurry causes the heavy particles to settle inward and downwards, and the light particles to the top layer. The particles are thus stratified in different velocity layers traveling in a curved path with the high velocity layer at the top. In general, particles with a higher density report to the inner edge of the spiral, while the ones with a lower density move towards the outer high wall (Figures 2.1 and 2.2). Depending on specific operation, two or three products can be obtained after spiral separation through the use of adjustable splitters, i.e. clean coal and refuse (two products), or clean coal, middling, and refuse (three products). The separation sharpness Ep (Probable Error) values for spiral separators are typically around 0.15 and the specific gravity cut points range from 1.7 to $2.0 \mathrm{SG}$. 


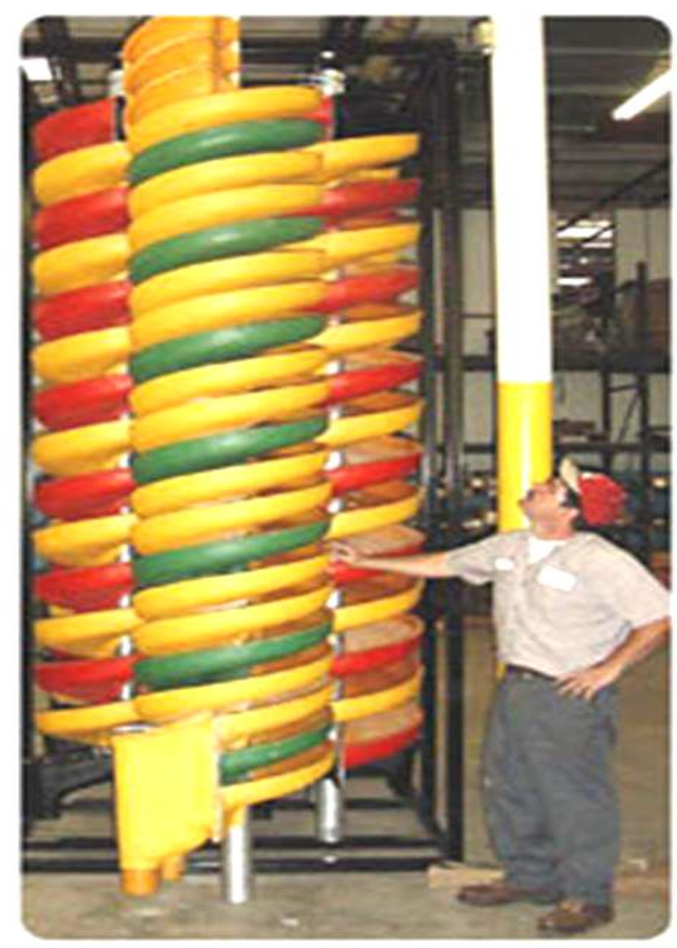

Figure 2.1 Coal spiral separation fundaments (Weldon, 1997).

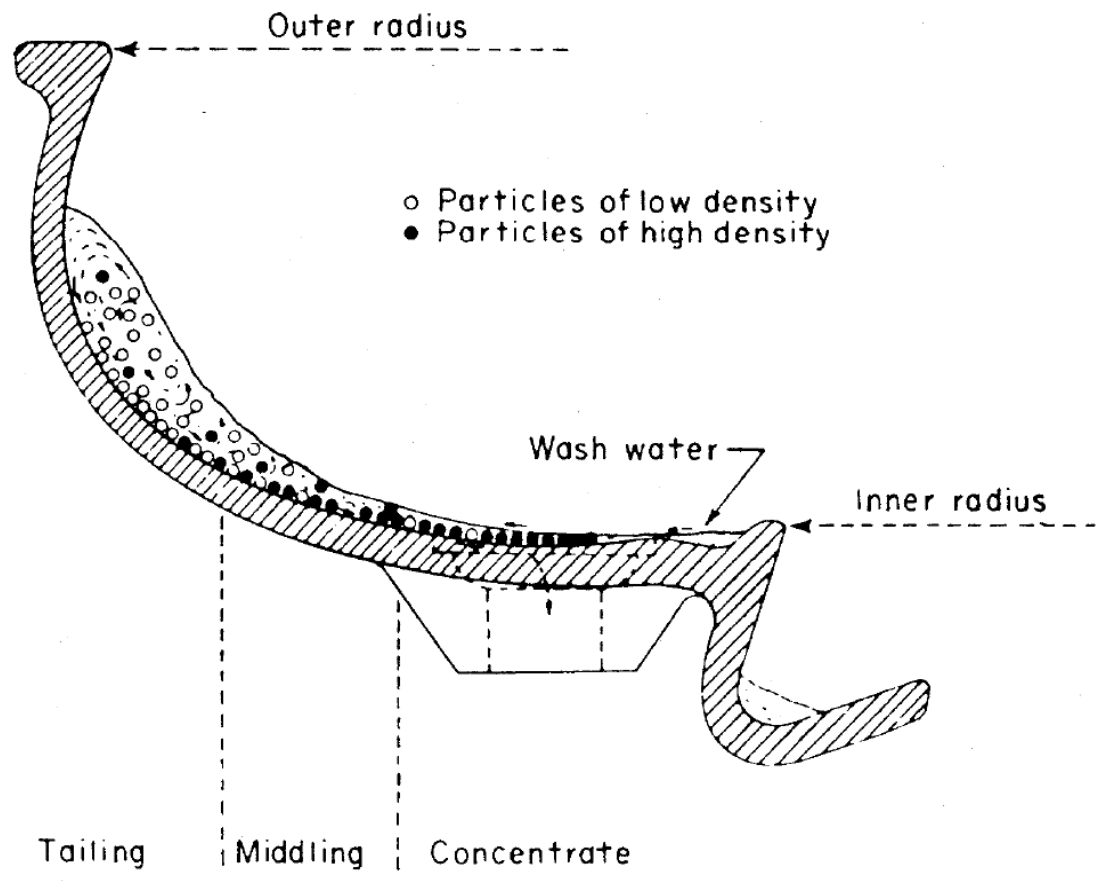

Figure 2.2 Cross-section of a spiral trough flow (Matthews et al., 1999). 


\subsection{Spiral design parameters}

The design parameters affecting the spiral separation performance include spiral pitch (vertical distance between two successive turns), trough slope and cross profile, and radius of the trough (Mikhail et al., 1988; MacHunter et al., 2003). Mikhail et al. (1988) summarized the general design parameters in Table 1.1. The compound spiral (in Figure 2.3) is essentially a two-stage, middlings re-cleaner circuit arranged on one spiral separator, where a short primary spiral and a short secondary spiral are positioned on the same center tube (MacNamara et al., 1995, 1996). The first stage clean coal and reject are removed. Then, the first stage middlings are repulped and retreated on the secondary spiral. This unique design provides the following advantages for compound spirals: lower cutpoints, reduced floor space, elimination of interstage pumping, and improved recovery (Weldon et al., 1997).

Table 1.1 Design parameters of spiral separator.

\begin{tabular}{|c|c|c|}
\hline Paramter & Design & Application \\
\hline Spiral pitch & $\begin{array}{l}\text { Small pitch } \\
\text { Large pitch }\end{array}$ & $\begin{array}{l}\text { - Small relative density difference } \\
\text { - Fine particle sizes } \\
\text { - High capacity } \\
\text { - Large relative density difference }\end{array}$ \\
\hline Trough profile & $\begin{array}{l}\text { Continuous } \\
\text { Compound }\end{array}$ & $\begin{array}{l}\text { - General applications } \\
\text { - Suitable for feeds containing small } \\
\text { percentage of heavy minerals }\end{array}$ \\
\hline Trough radius & $\begin{array}{l}\text { Large } \\
\text { Increasing }\end{array}$ & $\begin{array}{l}\text { - Treatment of fine particles } \\
\text { - Treatment of very wide size range }(2 \mathrm{~mm} \text { to } \\
0.05 \mathrm{~mm})\end{array}$ \\
\hline
\end{tabular}




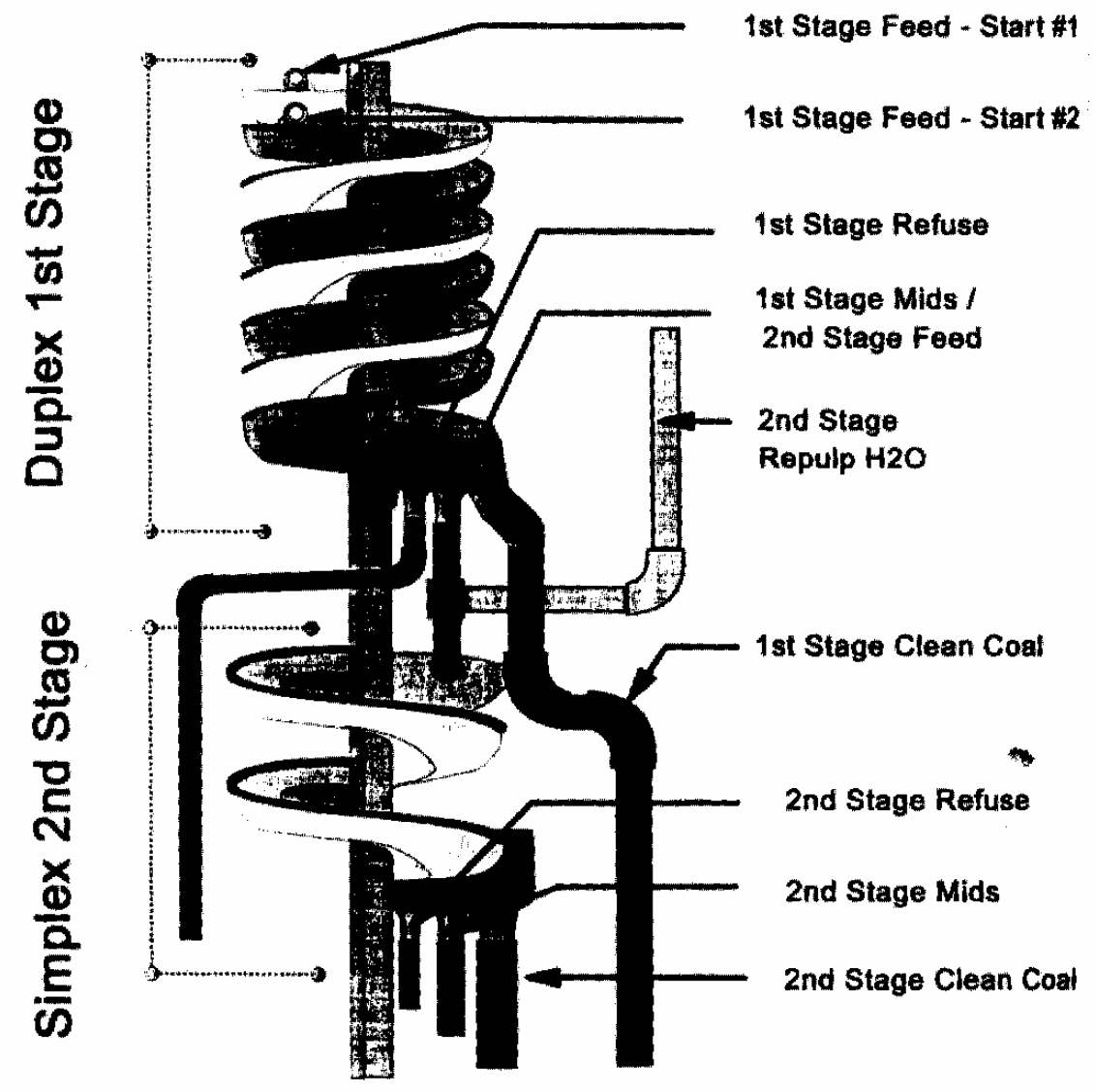

Figure 2.3 General Arrangement of a Duplex Compound Spiral (MacNamara et.al. 1996).

\subsection{Spiral operating parameters}

Once spiral separators are designed and installed in the plants, the spirals are lightweight, wear-resistant, and cost-effective gravity concentration equipment which has no moving parts, no reagent addition, and minimum maintenance requirement. The operating parameters which influence the spiral concentration performance include feed rate, percent solids, and particle size (Table 2.2). 
Table 2.2 Operation parameters of spiral separators.

\begin{tabular}{|c|c|}
\hline Paramter & Operation Conditions \\
\hline Feed rate & $\begin{array}{l}\text { - } 1-3 \text { tph (dry solids) } \\
\text { - High feed rate resulting in low separation efficiency } \\
\text { and high cut-point }\end{array}$ \\
\hline Percent solids & $\begin{array}{l}\text { - Limited influence on separation } \\
\text { - Usually } 20-40 \% \text { (by mass) } \\
\text { - Higher feed ash requires lower percent solids }\end{array}$ \\
\hline Particle size & $\begin{array}{l}\text { - Top size } 3 \mathrm{~mm} \text {, but } 1 \mathrm{~mm} \text { is preferable } \\
\text { - } 0.075 \mathrm{~mm}(200 \mathrm{mesh}) \text { is the effective separation limit } \\
\text { - Desliming is recommended }\end{array}$ \\
\hline
\end{tabular}

Total mass flow rate is one of the most important factors affecting the capacity and efficiency of a spiral in cleaning fine coal (Walsh and Kelly, 1992). Feed rate, especially the total volumetric flow rate, introduced onto a spiral has a significant effect on the performance of a spiral (Holland-Bratt, 1990). As the volumetric feed rate increased, the amount of entrained materials reporting to the outer wall increased, resulting in a decrease of separation efficiency. The misplaced coal particles had little change to escape the high velocity flow regime at the outer zone and ultimately report to the clean coal product. The effects of feed rate and feed solids on spiral performance were also studied by Mikhail et al. (1988). They found that feed rate actually had a greater effect on separation cutpoints than the position of splitter. The volumetric velocity of slurry down the spiral was increased if solids were held constant and feed rate was increased. The increased velocity led to an increase of centrifugal force exerted on the slurry particles, 
forcing more material to move toward the clean coal launder. Figure 2.3 illustrates the relationship between the feed rate and cut-point of a spiral separation.

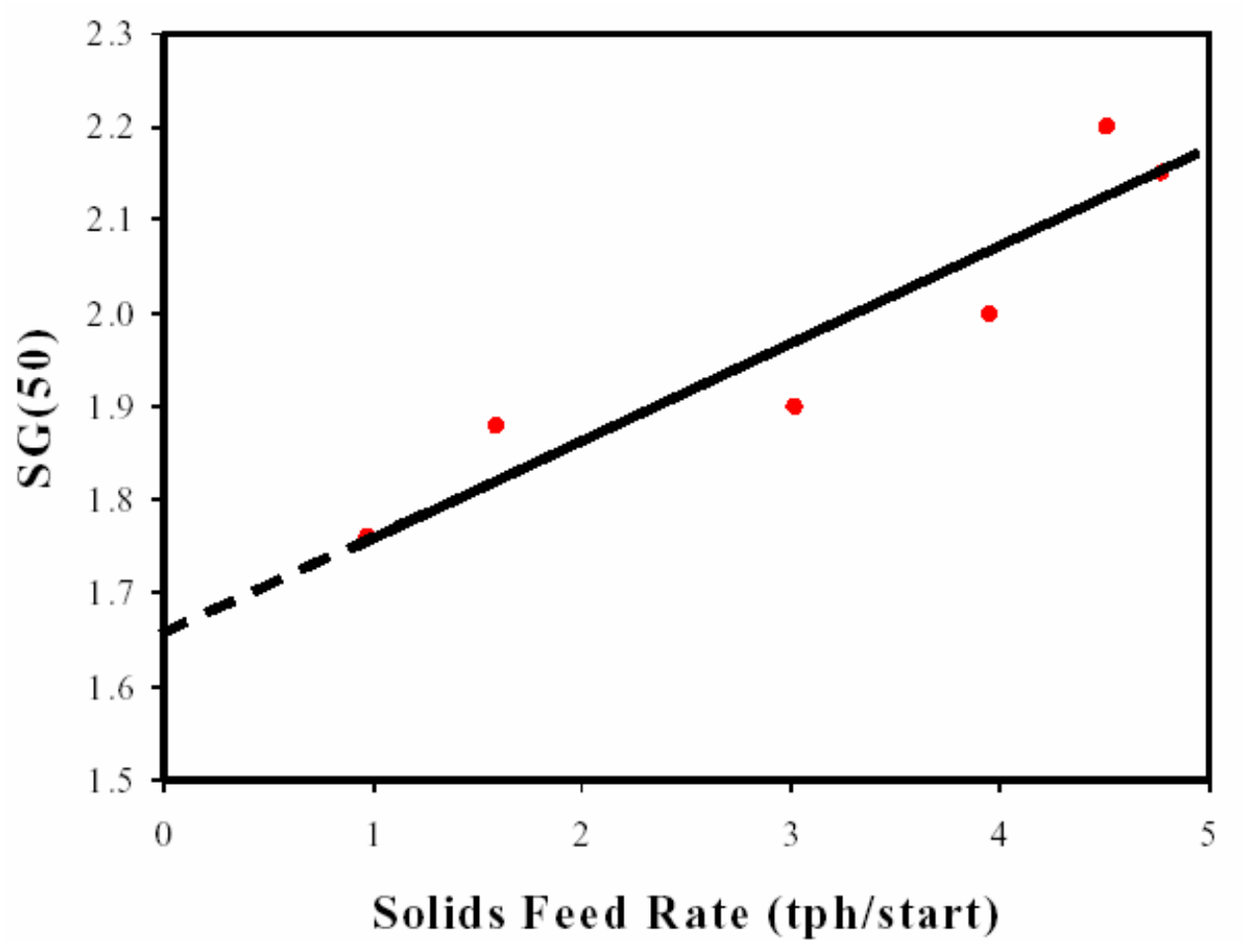

Figure 2.4 Feed rate versus cut-point of a spiral separation (Mikhail et al., 1988; Kohmuench, 2000).

\subsection{Advantage and disadvantage of spiral separators}

Spiral separator is one of the most effective devices for cleaning fine coals $(<1 \mathrm{~mm})$, with the following advantages (MacHunter et. al., 2003; Weldon, 1997):

- Low cost and minimum maintenance

- High separation efficiency 
- Ease of operation

The disadvantages of spiral separators include (MacHunter et. al., 2003; Kohmuench, 2000):

- Relatively high specific gravity cut-points (>1.7 SG)

- Relatively low unit throughput

- The need for multi-stage processing

- Limited acceptable feed size range

\subsection{Spiral configuration circuits}

As aforementioned, high specific gravity cutpoint (>1.7 SG) is a shortcoming of spiral separation. In particular, the specific gravity (SG) cutpoints of spiral separators are much higher than those of the dense medium vessels for coarse coal, which could result in either a loss of clean coal in tailings or a decrease in clean coal quality (DTI, 2001). To address this advantage, spirals are often employed in multi-stage circuits where the clean coal and/or middling streams from primary spirals are re-suspended and reprocessed in secondary spirals. In practice, there are a variety of circuit configurations for spiral separation. The common spiral configurations are as follows (Figure 2.4):

(a). Singe-stage rougher ((Figure 4 (a))

(b). Rougher-cleaner without recycle ((Figure 4 (b))

(c). Rougher-cleaner with middlings recycle ((Figure 4 (c))

(d). Rougher with middlings cleaner ((Figure 4 (d)) 

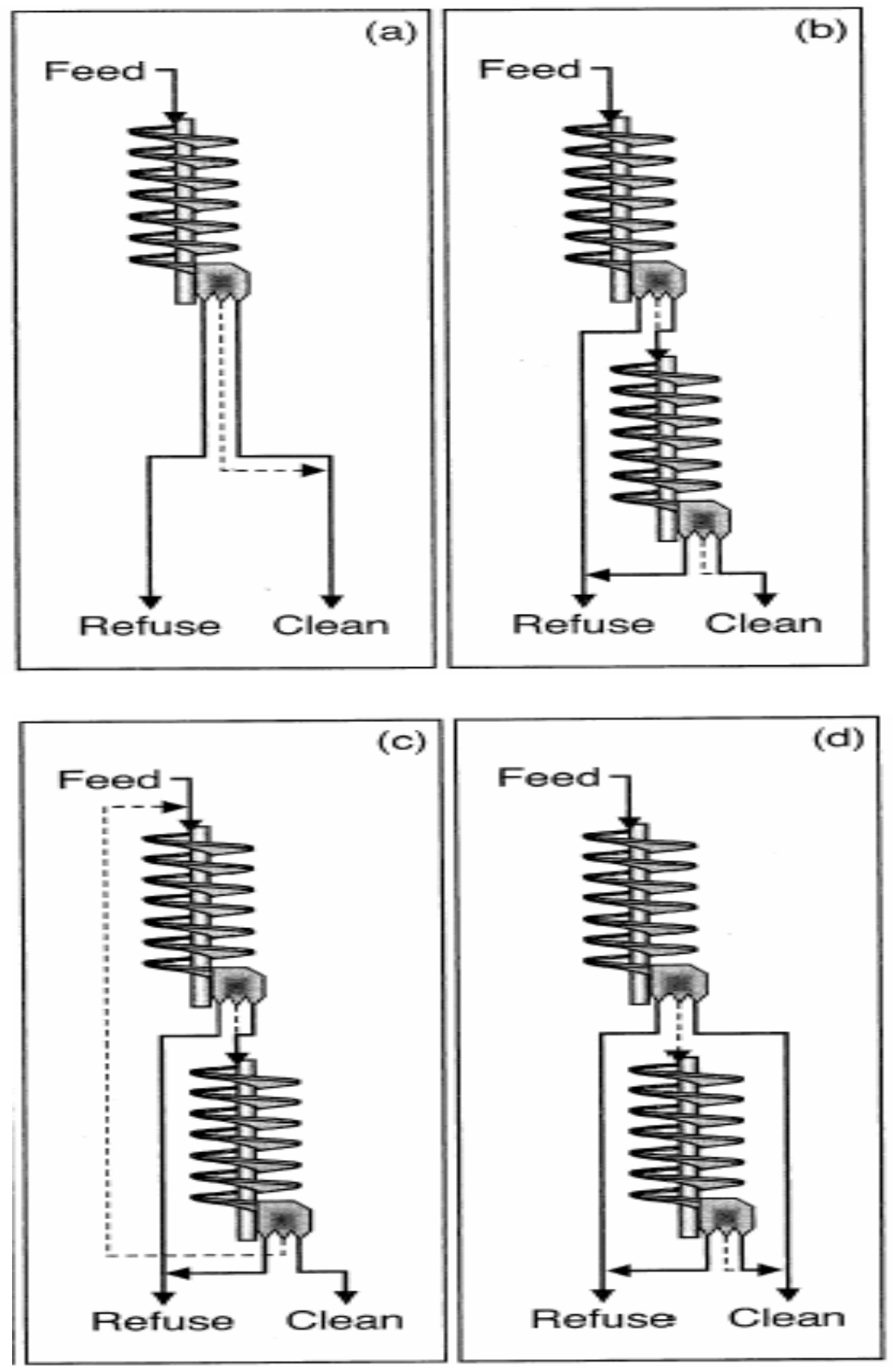

Figure 2.5 Circuit configurations of spiral separation for fine coal (Luttrell, 2003).

The separation performance for three (circuit a, b, and c) of the four configurations above are presented in Table 2.3 for the same industrial operation. The data indicated that single-stage (a) spirals produced the highest clean coal yield $(56.7 \%)$ with an 
unacceptably high ash content $(18.8 \%)$. The poor clean coal quality was caused by high specific gravity cutpoint (1.82 SG) and medium separation sharpness $(\mathrm{Ep}=0.18)$. Both two-stage rougher-cleaner circuits (b and $c$ ) significantly reduced the specific gravity cutpoints to 1.61 and 1.66 for circuit $\mathrm{b}$ and $\mathrm{c}$, respectively. Both of the two-stage circuits significantly reduced the ash content to around $9 \%$. Comparison between circuit $\mathrm{b}$ and $\mathrm{c}$ illustrated that circuit $\mathrm{c}$ (rougher-cleaner with middlings recycle) increased the clean coal yield from $40.6 \%$ to $46.3 \%$, and improved organic recovery efficiency from $83.4 \%$ to $94.3 \%$, with an acceptable sacrifice of separation sharpness (from 0.20 to 0.15 ). Overall, rougher-cleaner circuit with middling recycle (c) showed best separation performance.

Table 2.3 Industrial comparison of different spiral circuit configurations.

\begin{tabular}{|l|c|c|c|}
\hline \multicolumn{1}{|c|}{ Parameters } & $\begin{array}{c}\text { Single-stage (a) } \\
\text { (No recycle) }\end{array}$ & $\begin{array}{c}\text { Two stage (b) } \\
\text { (No recycle) }\end{array}$ & $\begin{array}{c}\text { Two stage (c) } \\
\text { (recycle) }\end{array}$ \\
\hline Circuit yield (\%) & 56.7 & 40.6 & 46.3 \\
\hline Circuit ash (\%) & 18.8 & 9.05 & 9.23 \\
\hline Separation sharpness (Ep) & 0.18 & 0.20 & 0.15 \\
\hline Organic Efficiency (\%) & 90.4 & 83.4 & 94.3 \\
\hline SG Cutpoint & 1.82 & 1.61 & 1.66 \\
\hline
\end{tabular}




\subsection{Fine Coal Spiral}

A significant inefficiency has been observed in coal preparation plants in processing $-1 \mathrm{~mm}$ fine coal. Conventional fine coal cleaning technologies typically provide relatively high separation density values of 1.8 and greater with the probable error values ranging from 0.15 to 0.20 . The high cutpoint makes it difficult to obtain high-quality, low-ash products. Although spirals are widely used for fine coal cleaning, they have the tendency to misplace significant amounts of mineral content into the clean coal product (Luttrell et al., 2003). The misplacement is often caused by particles getting trapped in the high velocity flow region along the outside wall of the spiral. The fluid flow rotates in a clockwise direction within the lower section of the spiral profile. This flow carries lighter particles back to the outside wall of the spiral where they are recovered, while heavier particles settle and are carried to the inside of the spiral where they are rejected. In contrast, the fluid flow rotates in the opposite counter-clockwise direction within the upper section of the profile. The two rotating flow patterns converge at a single point (called the critical separation line). Particles of rock that enter the upper zone tend to settle against the wall and are held by the upward flow. Consequently, it is very difficult for these particles to pass across the critical separation line. These high-ash particles eventually report to the low-density stream resulting in a low-quality coal product.

Recently, several advances in fine coal separators has been made and fine coal spirals are one of the most popular methods to be used to clean the $-1 \mathrm{~mm}+0.149 \mathrm{~mm}$ size-fraction of coal (Barbara, 2004). In recent years, improved performance has been 
obtained in a rougher-cleaner with middlings recycle circuit by using two stages spiral configures. This circuit has been mimicked in a single spiral assembly (the SX7 spiral) by Multotec Process Equipment Ltd of Spartan, South Africa. Successful applications of this spiral are achieved in several US states such as Pennsylvania, West Virginia, Kentucky, Virginia and Illinois, with decreased clean coal ash and sulfur contents (Barbara, 2004). These installations clean a typical $-1 \mathrm{~mm}+0.149 \mathrm{~mm}$ fraction of raw coal and the rejects are washed with water-only cyclones. The two-stage spirals have been employed for ultrafine coal cleaning to clean the $-0.149 \mathrm{~mm}+0.044 \mathrm{~mm}$ fraction.

SX7 spirals were developed. Four spiral turns are followed by the removal of a primary refuse and re-mixing of the middlings and clean coal. No water is added to the remixer (or repulper). The middlings and clean coal then are treated on three additional spiral turns. A splitter at the bottom of the spiral allows removal of a secondary refuse that can be combined with the primary refuse. A middling can also be collected and fed back to the feed for re-processing or can be combined with the clean coal product.

The two-stage circuit for fine coal cleaning decreased the $\mathrm{E}_{\mathrm{p}}$ value from around 0.15 to 0.135 , which enhanced organic efficiency by five percentage points. 

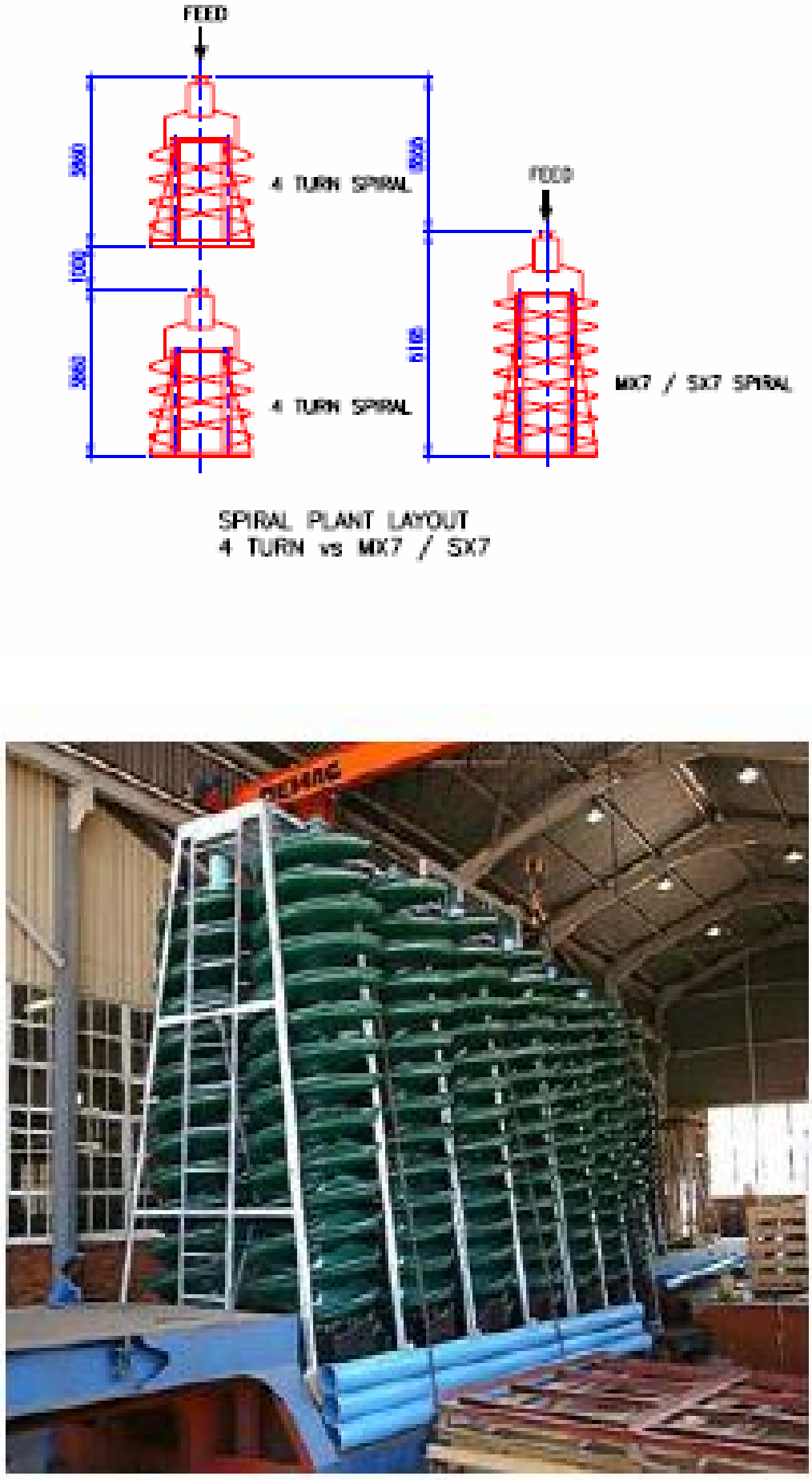

Figure 2.6 The SX7 spiral by Multotec Process Equipment Ltd of Spartan 
Coal Leader, July 2003 reports that Spiral circuit yield increase of 5.7\% ; at 45 tph, this increase at $\$ 25 /$ ton and 5,500 tpy gives $\$ 350,000 /$ year and spiral cut point dropped to 1.66 s.g., allowing the heavy medium s.g. to increase giving 13 tph more clean coal in that circuit for a total impact of $\$ 1.79$ million per year.

Froth flotation is generally used to the $-0.149 \mathrm{~mm}$ size fraction of coal in the US. However, in some cases froth flotation is not an option due to the relatively low coal rank, increased flotation reagent costs, and difficulty in froth dewatering. Significant research effort has focused on the development of density-based separators over the past two decades for cleaning coal having a particle size below $0.149 \mathrm{~mm}$. To address some of these concerns, Larry Watters and Daniel Placha (2006) from Sedgman LLC developed an ultrafine spiral circuit for cleaning the $-0.149 \mathrm{~mm}+0.044 \mathrm{~mm}$ size fraction of coal. They applied a system and method for cleaning ultra-fine raw coal with spiral concentrators. The system includes multiple pre- and post-classification systems to size the finer sized raw mineral to develop a pre-sized mineral fraction within a first size range (approximately $0.15 \mathrm{~mm}$ by $0.044 \mathrm{~mm}$ ). The pre-sized mineral fraction is fed to at least one spiral concentrator, wherein the at least one spiral concentrator separates the pre-sized mineral fraction into clean mineral and refuse by specific gravity. Additionally, residual minus $0.044 \mathrm{~mm}$ particles may be removed from the clean mineral output by a post classification system.

Honaker et al (2007) studied the optimization of spiral concentrator performance for ultrafine coal cleaning using a single-start LD4 spiral (MDL, Australia). Empirical models were developed to accurately describe the effect of three key operating values and their interactive relationships when treating coal in the size range of $-210+44 \mu \mathrm{m}$. The 
three key parameters were volumetric feed rate, feed solids concentration, and splitter position. The models were further used to identify sets of optimum parameter values that will maximize combustible recovery over a range of product ash values. The empirical data clearly shows that the volumetric feed rate played a critical role in the combustible recovery and product ash. The feed solid concentration also had a significant effect on product ash content. Splitter position and volumetric flow rate jointly influenced the product grade. Maximum recovery was predicted at the highest volumetric feed rates and lowest feed solid concentration while the minimum product ash content is realized at the opposite end of the parameter value ranges (Honaker, 2007). In the in-plant studies, the spiral concentrator was found to be an effective technology for cleaning coal as fine as 44 $\mu \mathrm{m}$. The optimum volumetric flow rate was below $60 \mathrm{l} / \mathrm{min}$ while the optimum solids concentration was approximately $12 \%$ by weight, which equates to a mass flow rate of $0.6 \mathrm{t} / \mathrm{h}$.

Benusa and Klima (2008) evaluated the performance of a multistage Multotec SX7 spiral concentrator in treating ultrafine bituminous coal in southwestern Pennsylvania. They found that the spiral was able to achieve acceptable separation over a wide range of flow rates and solids concentrations. As opposed to the solids concentration, the flow rate is more influential on the variation of yield and ash value. As the flow rate decreased, the yield and ash value of the clean coal were reduced, resulting in increased yields of the middlings and refuse. The results indicated very little deterioration in spiral performance with the undeslimed and deslimed feed material (-500mesh) even when the feed contained $\sim 50 \%$ of -500 mesh material. However, the ash value of the clean coal product was reduced if the -500 mesh material was removed. 
They also evaluated the performance of a Multotec SX7 two-stage spiral when processing three different feed materials of fine anthracite refuse the thickener feed slurry (nominal $-1.2 \mathrm{~mm}$ ), the thickener underflow slurry, and a prepared nominal $1.2+0.025 \mathrm{~mm}$ feed with deslimed thickener feed using a 102-mm diameter Krebs cyclone. The feed ash value could be reduced from $71 \%$ to $21 \%$ for the $+0.025 \mathrm{~mm}$ material and the ash value the refuse was $91 \%$. Regardless of deslime, the $+0.025 \mathrm{~mm}$ material can be cleaned very well. The separation occurred even with the thickener underflow, which had been treated with flocculant. The $-0.025 \mathrm{~mm}$ material reported in clean coal and refuse are approximately proportional to the water.

When correctly configured and properly operated, fine spirals are generally capable of maintaing good recoveries of clean coal. However, Luttrell et al. conducted field studies and found that spirals in US applications were often operated under the conditions far from the optimum. They summarized the shortcomings of US industrial spiral circuits as 1) Ineffective for small particles $(<0.15 \mathrm{~mm})$, 2) low unit throughput capacity $(<3.5 \mathrm{tph} / \mathrm{start}), 3)$ high specific gravity cutpoint $(>1.9), 4)$ misplacement of rock to clean coal, 5) sensitivity to feed distribution and solids loading, and 6) the requirement of desliming of clean coal. They suggested that the performances of fine spirals can be improved by optimizing the solids mass rate, slurry flow rate, feed solids content, splitter positions, feed distribution, and circuit configures. 


\section{Chapter 3}

\section{Experiments}

\subsection{Description of coal preparation plant}

Shade Coal Preparation Plant, PBS Coals, Inc., is located near Central City, Pennsylvania. The plant cleans run-of-mine coal at a rate of $600 \mathrm{tph}$, producing about 2,500 tons of clean coal per shift. Besides spirals, the preparation plant flowsheet consists of a heavy-media bath, heavy-media cyclones, and hydrocyclones. Figure 3.1 presents the partial flowsheet of the Plant associated with spiral separation. Two sets of spirals are installed at the plant. One set of 8 triple-start spirals (Spiral I in Figure 3.1) treat the underflow of 15-inch Multotech hydrocyclones (particle size $<1.0 \mathrm{~mm}$ ), are referred to as "coarse spiral" in the text. The feed rate is around 130 tph and the slurry solids content is about $30 \%$. Three products are generated from coarse spiral: clean coal, refuse, and middlings. The middlings of coarse spiral are recycled to 15 -inch hydrocyclones. The other set consists of 8 triple-start spirals (Spiral II in Figure 3.1), cleaning the underflow of 10-inch deslime hydrocyclones (particle size $<0.37 \mathrm{~mm}$ ), and is referred to as "fine spiral" in the text. The feed rate for fine spiral is 25 tph and slurry contains $11 \%$ solids, indicating both mass feed rate and volumetric feed rate are less than those of fine spiral. The middlings of fine spiral are mixed with clean coal as final product. Consequently, only two products are from fine spiral: clean coal and refuse. 


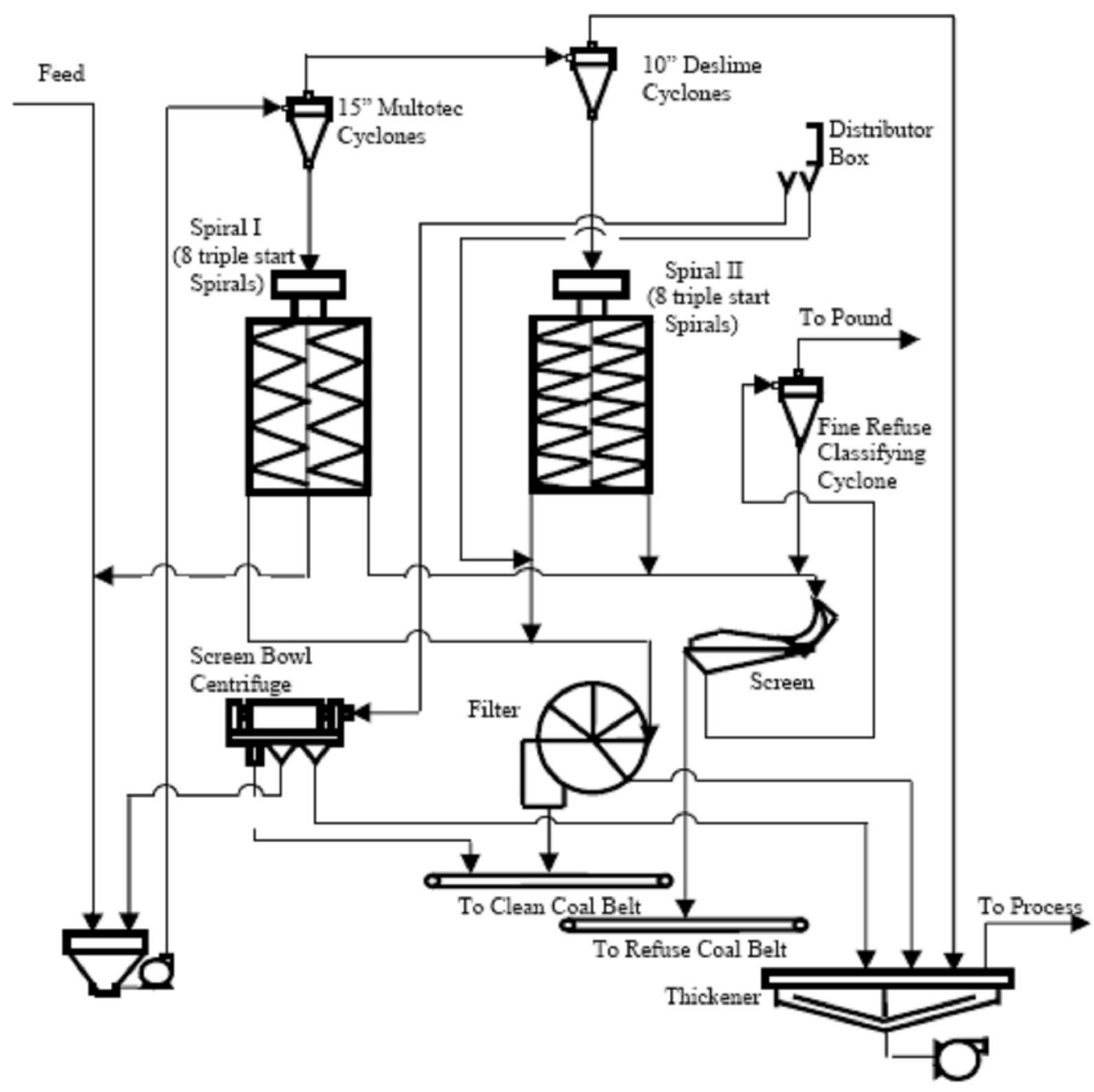

Figure 3.1 Spiral separation flowsheet at Shade Coal Preparation Plant

\subsection{Sampling collection and preparation}

Eight buckets of wet coal samples were collected from Shade Coal Preparation Plant, including the feed, clean coal, refuse, and middlings for fine spiral and coarse spiral, respectively. After settling, the samples were decanted to remove supernatants. Then, the samples were dried in ventilation oven at $50{ }^{\circ} \mathrm{C}$. Once dried, each sample was mixed to 
achieve homogeneity and was split to preparation sub-samples for further testing (size analysis and washability tests).

\subsection{Washability test}

Washability tests are carried out for eight samples of feed, clean coal, refuse, and middlings of fine spiral and coarse spiral. Representative samples were taken for this test. Float-sink analysis was performed on these size intervals using LMT (Lithium Metatungstate) liquids with specific gravities of 1.3, 1.4, 1.5, 1.6, 1.7, and 1.8. Details of the experimental procedures are in the Appendix A (Operating Procedures).

\subsection{Size distribution analysis}

Size distribution analysis is conducted for each size fraction of the above eight samples to evaluation the effectiveness of spiral separation. The total number of tests equals to 5 (sizes) $\times 6$ (densities $) \times 8$ (samples $)=240$. The following sieves are used for coarse spiral: $+1.190 \mathrm{~mm},-1.190 \mathrm{~mm}+0.420 \mathrm{~mm},-0.420 \mathrm{~mm}+0.210 \mathrm{~mm},-0.210$ $\mathrm{mm}+0.149 \mathrm{~mm}$ and $-0.149 \mathrm{~mm}$. For fine spirals, the sieves of $+0.210 \mathrm{~mm},-0.210 \mathrm{~mm}$ $+0.149 \mathrm{~mm},-0.149 \mathrm{~mm}+0.074 \mathrm{~mm},-0.074 \mathrm{~mm}+0.044 \mathrm{~mm}$ and $-0.044 \mathrm{~mm}$. Wet sieving method was used for size distribution analysis. This method uses water as a medium for facilitating the segregation of the sample into particle sizes. 


\section{Chapter 4}

\section{Results and Discussion}

\subsection{Performance of fine spiral}

\subsubsection{Products of fine coal spiral}

Fine spiral consists of 8 triple-start spirals, cleaning the underflow of 10-inch deslime hydrocyclones. The feed rate of fine spiral is 25 tph and slurry contains $11 \%$ solids. The overall performance of fine spiral is presented in Table 4.1. The fine spiral is able to recovery $65.5 \%$ of the deslime hydrocyclone underflow as clean coal with an ash content of $8.26 \%$. The ash contents for the refuse and middlings are $15.26 \%$ and $16.28 \%$, respectively, indicating a similar ash content for both products. The similar ash contents in the refuse and middlings could be caused by the improper position of splitter between them (too close to the inner rim). In the plant, middlings are combined with clean coal as one product (clean coal). Although this combination can lead to an increase in clean coal recovery $(74.8 \%)$, the ash in the middlings may result in a decrease in clean coal quality (Ash 9.26\%). Based on the ash contents in Table 4.1, it is recommended that the middlings be mixed with refuse, or position adjustment of the splitter be made. 
Table 4.1 Summary of the performance of fine spiral.

\begin{tabular}{lcc}
\hline \multicolumn{1}{c}{ Product } & Ash, \% & Yield, \% \\
\hline Clean Coal & 8.26 & 65.5 \\
Refuse & 15.26 & 25.2 \\
Middlings & 16.28 & 9.3 \\
Feed & 10.77 & 100 \\
Clean coal + middlings & 9.26 & 74.8 \\
\hline
\end{tabular}

The direct ash percentages of fine spiral products by specific gravity interval are presented in Figure 4.1. The direct weight percentages of fine spiral products by specific gravity interval are presented in Figure. 4.2. As shown in Figure 4.1, the ash content of clean coal shows lower value than those of the middlings and refuse. The ash contents of three products are relatively high at less than 1.30 specific gravity interval. The ash contents increases slightly between 1.30 and 1.70 specific gravity intervals and increases significantly at larger than 1.70 specific gravity interval. For the fraction with specific gravity $<1.30$, the relatively high ash contents could be due to the higher weight percentages (Figure 4.2). Fine slime particles in the slurry are difficult to settle and hence report to the small specific gravity interval. For several specific gravity intervals $(<1.30$, $1.40-1.50,1.50-1.60,1.60-1.70)$, the ash contents for middlings are actually greater than those of the refuse, indicating there is misplaced refuse in the middlings.

As shown in Figure 4.2, materials within two specific gravity intervals $(<1.30$ and $>1.70$ ) contribute the most to the makeup of all three product. For clean coal, the high weight percentage of $>1.70$ specific gravity interval indicates that small, but heavy, minerals are misplaced into clean coal streams. For the refuse, the high weight percentage 
of $<1.30$ specific gravity interval illustrates that relatively large, but light, clean coal are entrained into the refuse streams. The existence of misplaced materials in clean coal and the refuse demonstrates that there are great potentials for performance improvement through optimization of operational conditions (feed rate, slurry solids content, and position of splitters etc.)

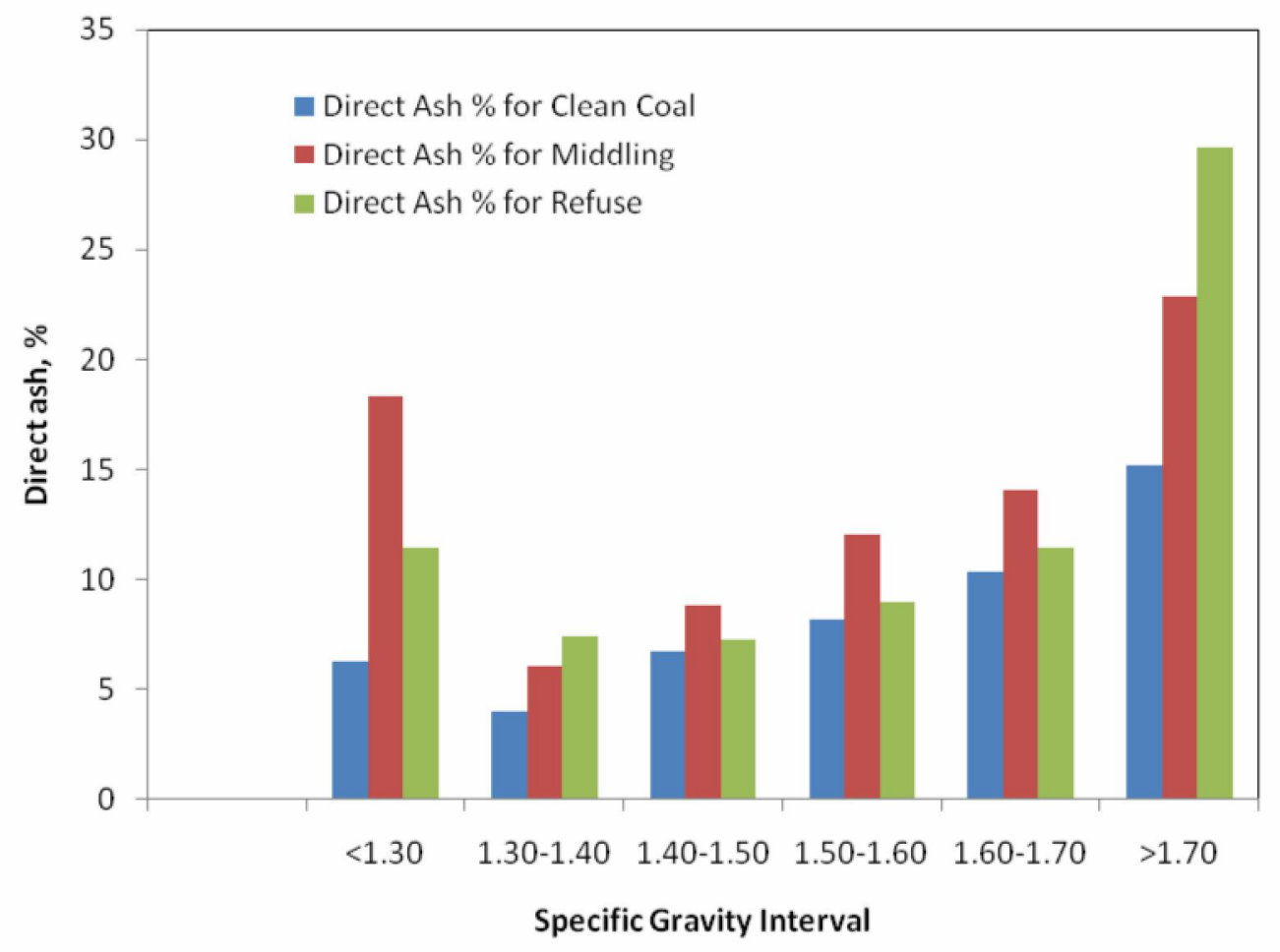

Figure 4.1 Direct ash content for fine spiral by specific gravity interval. 


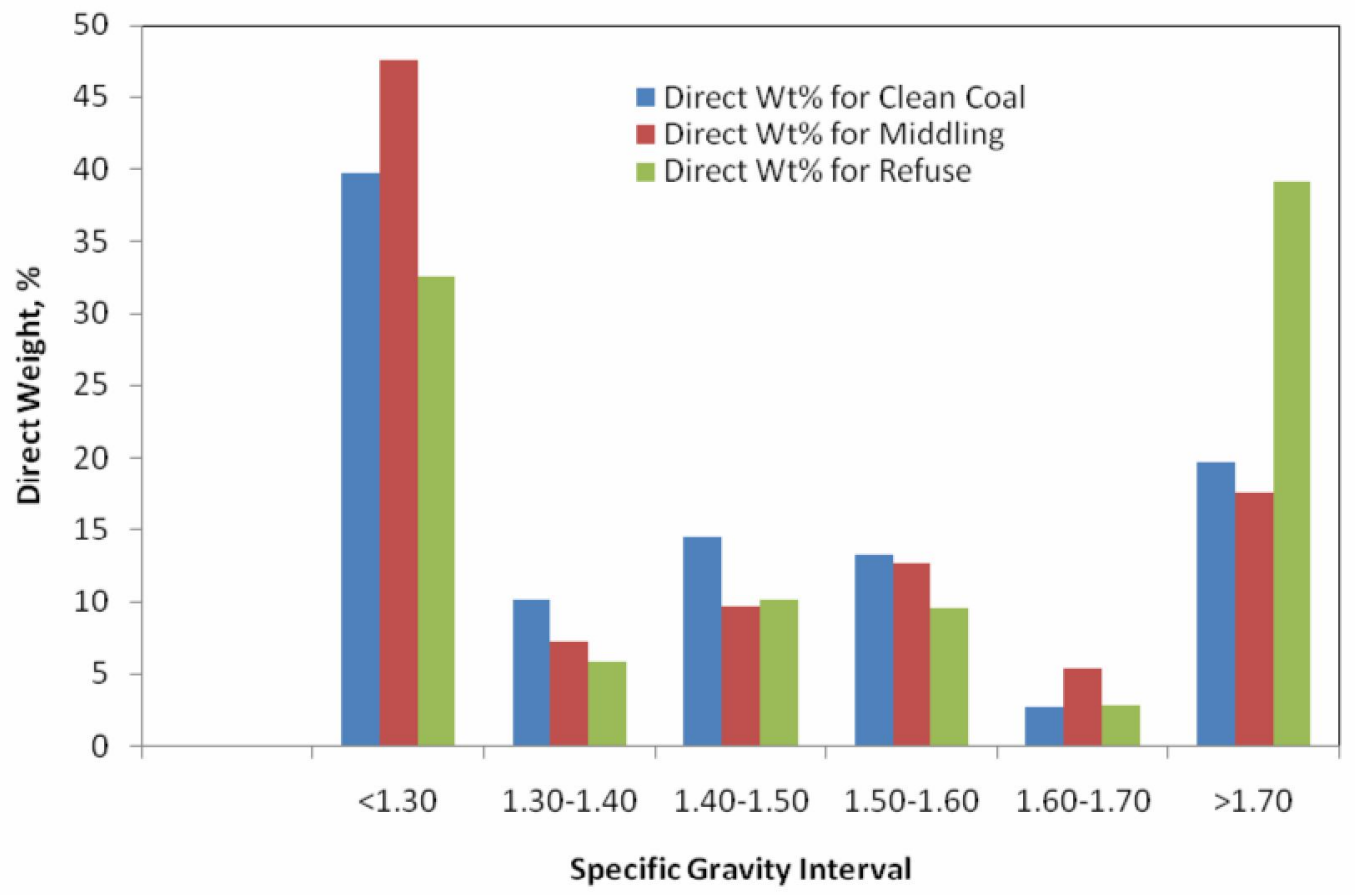

Figure 4.2 Direct weight percent for fine spiral by specific gravity interval.

\subsubsection{Fractional Recovery}

Presented in Figures 4.3 to 4.7 are the distribution curves for the fine spiral clean coal and combined clean coal (clean coal + middlings) at the following size intervals $+0.210 \mathrm{~mm},-0.210 \mathrm{~mm}+0.149 \mathrm{~mm},-0.149 \mathrm{~mm}+0.074 \mathrm{~mm},-0.074 \mathrm{~mm}+0.044$ $\mathrm{mm}$ and $-0.044 \mathrm{~mm}$. The distribution factors $(65 \sim 75 \%)$ of low specific gravity material $(<1.4)$ reporting to clean coal for size intervals of $+0.210 \mathrm{~mm},-0.210 \mathrm{~mm}+0.149 \mathrm{~mm}$, and $0.149 \mathrm{~mm}+0.074 \mathrm{~mm}$ (Figures 4.3, 4.4, and 4.5) are lower than those for size intervals of $0.074 \mathrm{~mm}+0.044 \mathrm{~mm}$, and $-0.044 \mathrm{~mm}(75 \sim 90 \%$, Figures 4.6 and 4.7$)$, indicating that a portion of coarse clean coal $(>0.074 \mathrm{~mm})$ is entrained into the refuse. The distribution factor of high specific gravity material $(>1.7)$ is $40 \sim 50 \%$ for size intervals of $<0.210 \mathrm{~mm}$ 
(Figures 4.4, 4.5, 4.6, and 4.7), demonstrating that significant amount of fine mineral particles (slime) is misplaced into clean coal with slurry flow. These findings are consistent with the results obtained in Section 4.1.1. As expected, when the middlings stream is combined with clean coal, there is a slight decrease in the amount of lost clean coal and the amount of lost high density material (mineral contents). The distribution curves for composite size intervals reveals similar trend (Figure 4.8). The distribution factors for light materials (specific gravity $<1.4)$ and heavy materials $(>1.6)$ are $65 \sim 75 \%$ and $55 \sim 60 \%$, respectively, illustrating the existence of misplaced clean coal and mineral contents.

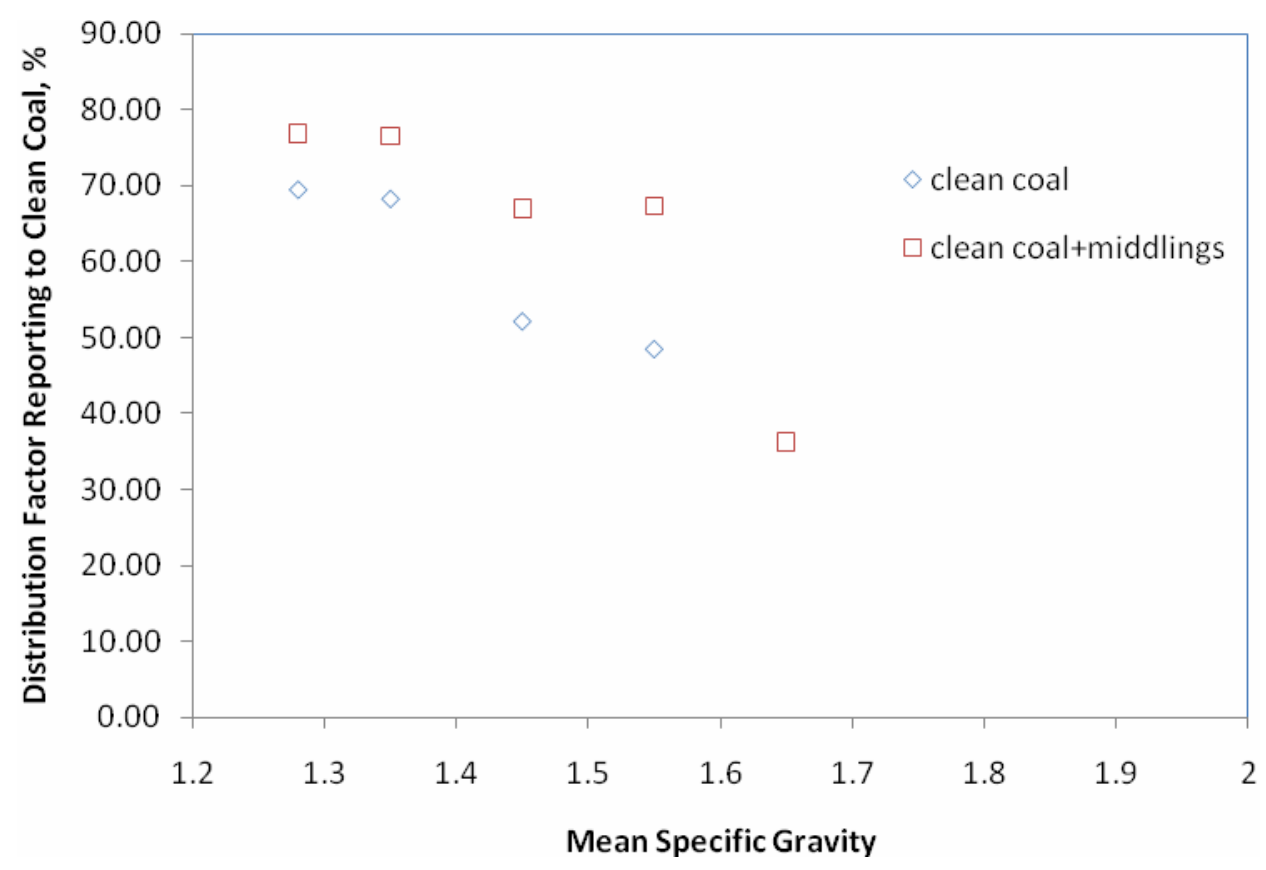

Figure 4.3 Distribution Curve for Fine Spiral (Size Distribution: $+0.210 \mathrm{~mm}$ ). 


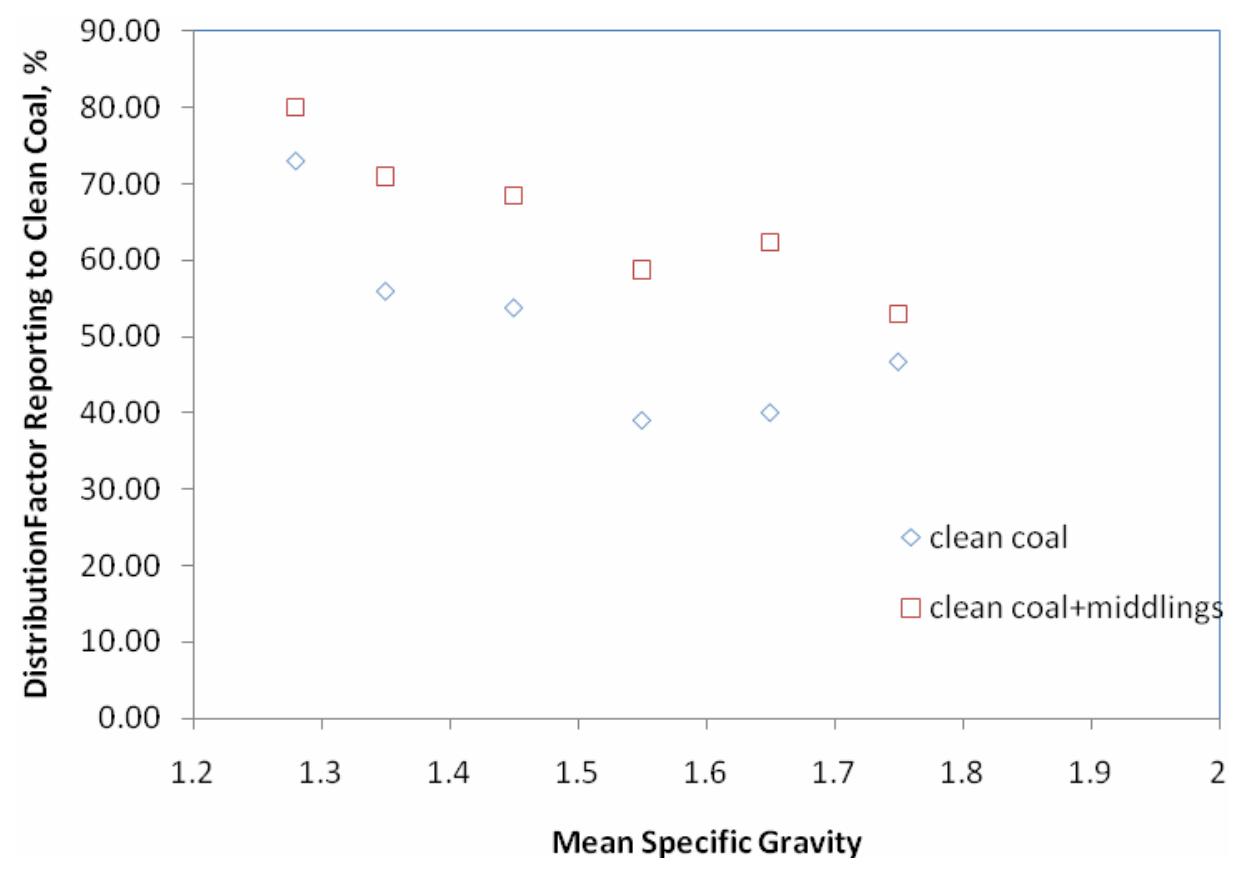

Figure 4.4 Distribution Curve for Fine Spiral (Size Distribution: $-0.210 \mathrm{~mm}+0.149 \mathrm{~mm}$ ).

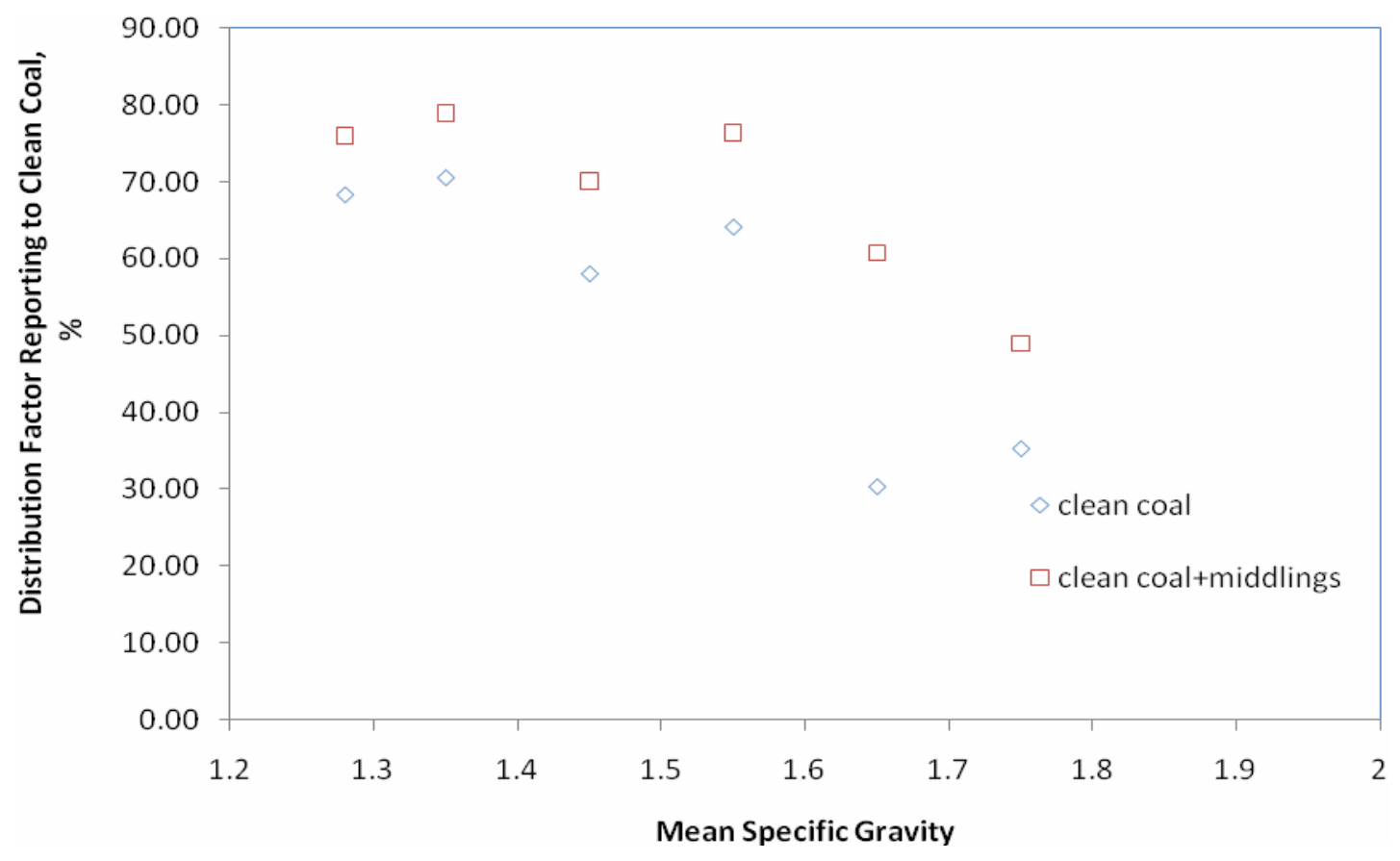

Figure 4.5 Distribution Curve for Fine Spiral (Size Distribution: $-0.149 \mathrm{~mm}+0.074 \mathrm{~mm}$ ). 


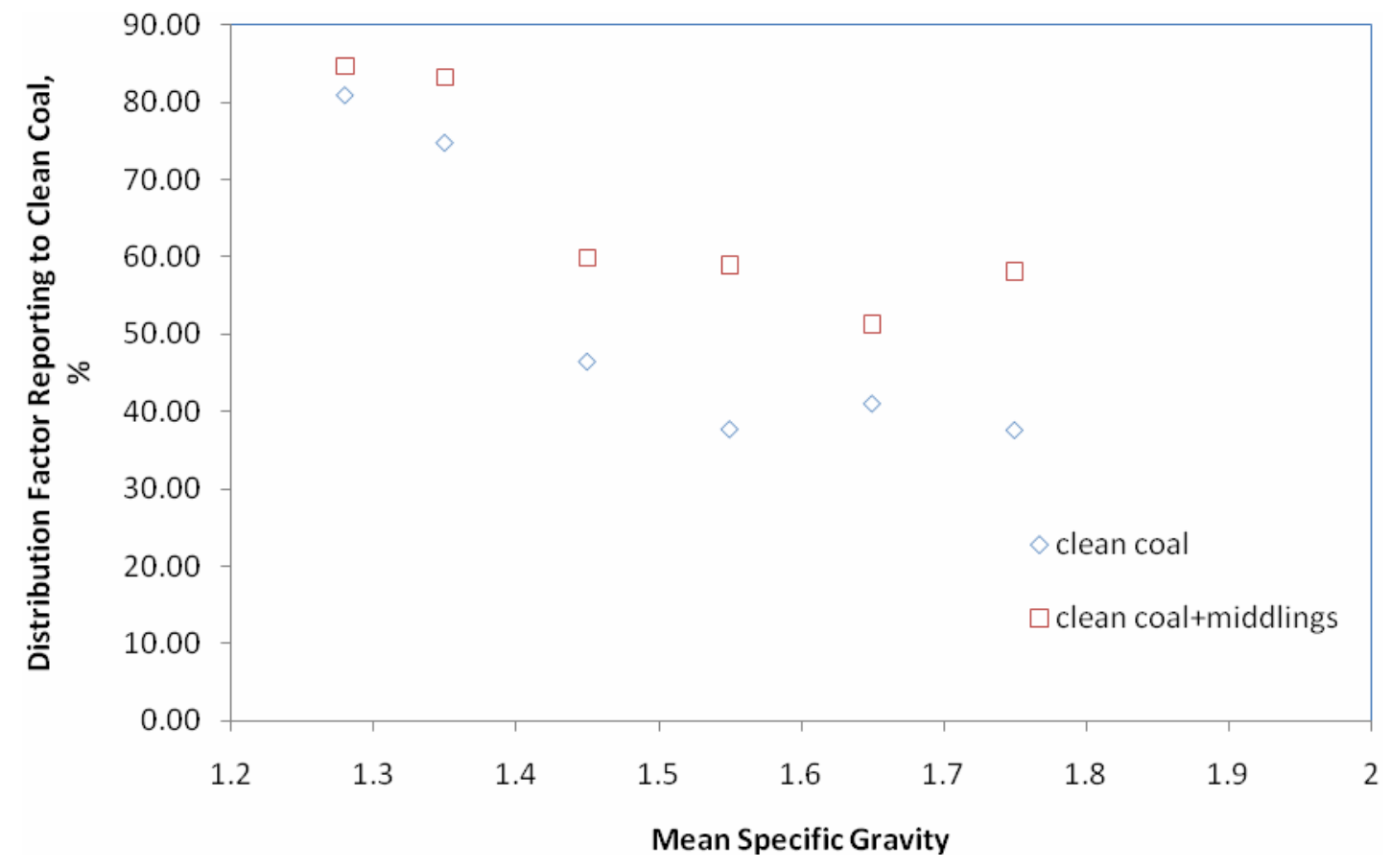

Figure 4.6 Distribution Curve for Fine Spiral (Size Distribution: $-0.074 \mathrm{~mm}+0.044 \mathrm{~mm}$ ).

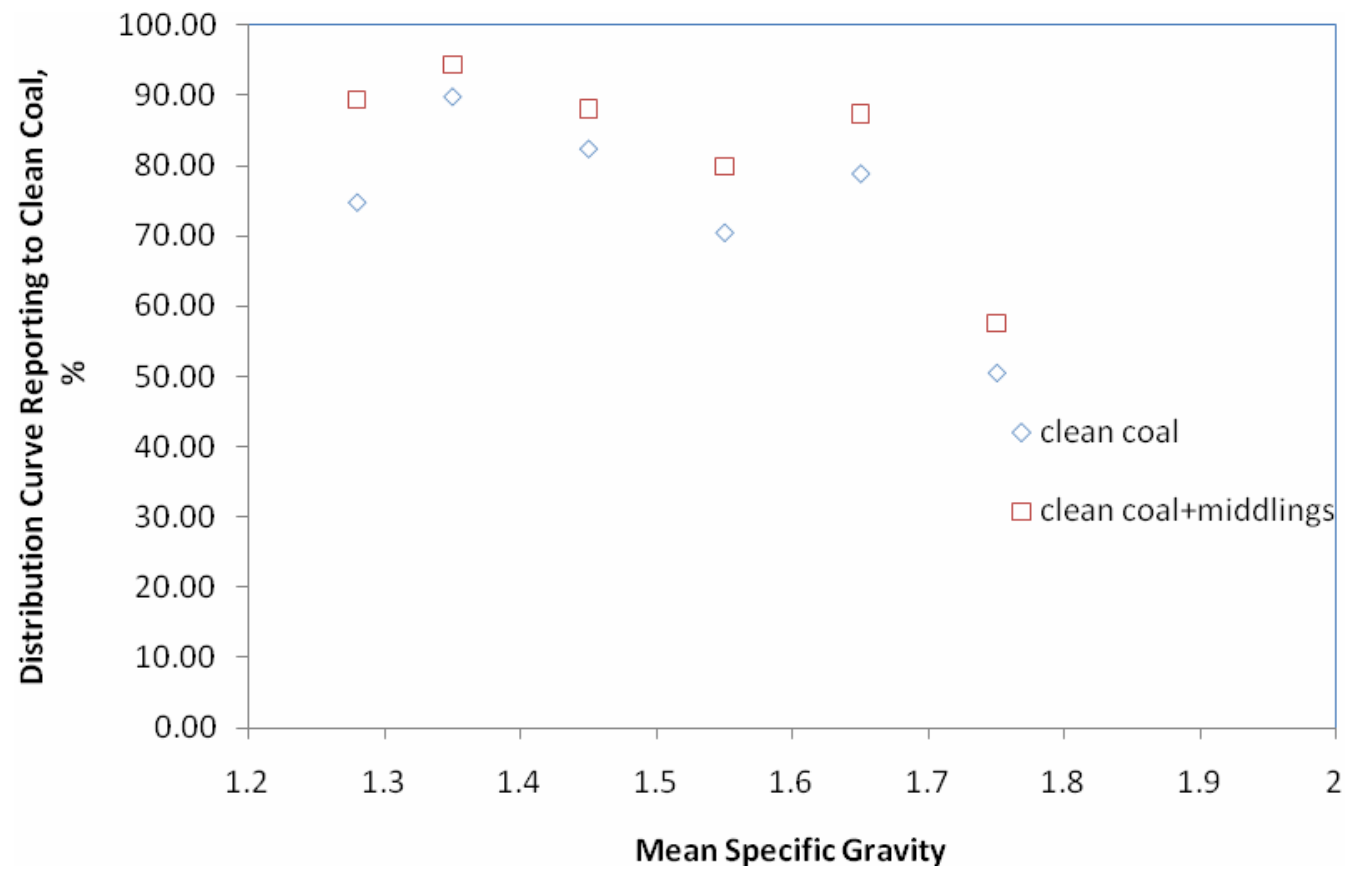

Figure 4.7 Distribution Curve for Fine Spiral (Size Distribution: -0.044mm). 


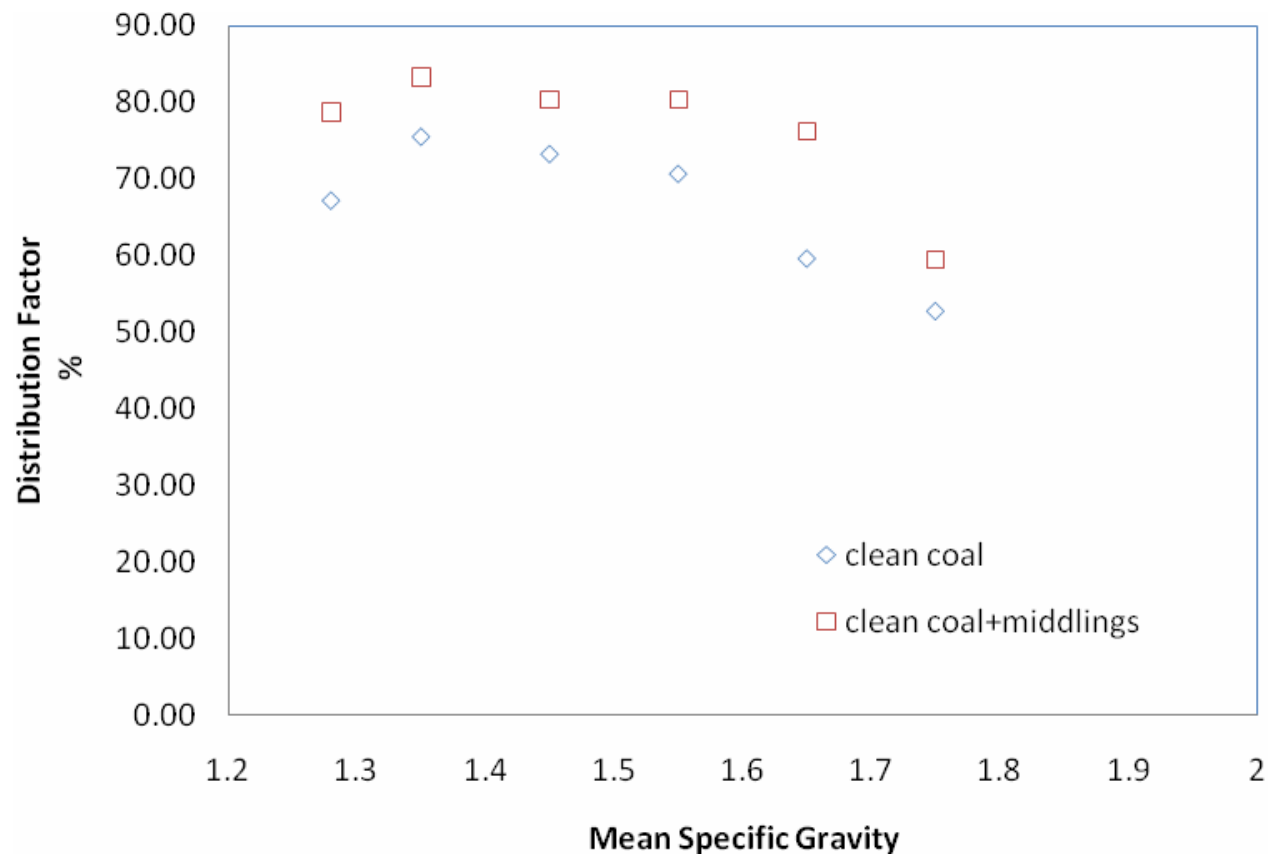

Figure 4.8 Distribution Curve for fine spiral coal (composite).

\subsection{Performance of coarse spiral}

\subsubsection{Coarse coal spiral products}

Coarse spiral consists of 8 triple-start spirals treating the underflow of 15-inch Multotech hydrocyclones (particle size $<1.0 \mathrm{~mm}$ ). Three products are generated from coarse spiral: clean coal, refuse, and middlings. The overall performance of coarse spiral is presented in Table 4.2. The coarse spiral is able to recovery $61.5 \%$ of the 15 -inch hydrocyclone underflow as clean coal with an ash content of $7.26 \%$. The ash contents for the refuse and middlings are $11.96 \%$ and $9.32 \%$, respectively. It is to note that the yield 
of middling is $26.2 \%$, which is significantly higher than that of fine spiral $(9.30 \%$, Table 4.1). In the plant, middlings are recycled to 15 -inch hydrocycle. However, as indicated from Table 4.2, combination of clean coal and middling can results in combined clean coal with a yield of $87.7 \%$ containing $7.88 \%$ ash, which is lower than that of the clean coal from the fine spiral. Therefore, it is recommended that the middlings be mixed with clean coal to obtain combined clean coal with satisfactory ash content. If low ash content is desired, the position of splitter between middlings and the refuse can be adjusted towards the outer rim, leading to reduced ash content and clean coal yield.

Table 4.2 Summary of the performance of coarse spiral.

\begin{tabular}{lcc}
\hline \multicolumn{1}{c}{ Product } & Ash, \% & Yield, \% \\
\hline Clean Coal & 7.26 & 61.5 \\
Refuse & 11.96 & 12.3 \\
Middlings & 9.32 & 26.2 \\
Feed & 8.37 & 100 \\
Clean Coal +middling & 7.88 & 87.7 \\
\hline
\end{tabular}

The direct weight percentages of coarse spiral products by specific gravity interval are presented in Figure. 4.9. As shown in Figure 4.9, the light material (specific gravity $<1.3$ ) contribute to $73 \%$ of the middlings, and $67 \%$ of clean coal, which is a strong indication that middling should be mixed with clean coal as one clean coal product instead of recycling back to 15 -inch hydrocyclone, which is higher than the weight percentages for clean coal and middlings are $67 \%$ and $73 \%$. 
The direct ash percentages of coarse spiral products by specific gravity interval are presented in Figure 4.10. As expected, the higher the specific gravity intervals, the higher ash content is observed for clean coal, the middlings, and the refuse. Since the intervals > 1.4 contribute little to the weight percentage (Figure 4.9), the very high ash content does not lead to significant ash increase in clean coal.

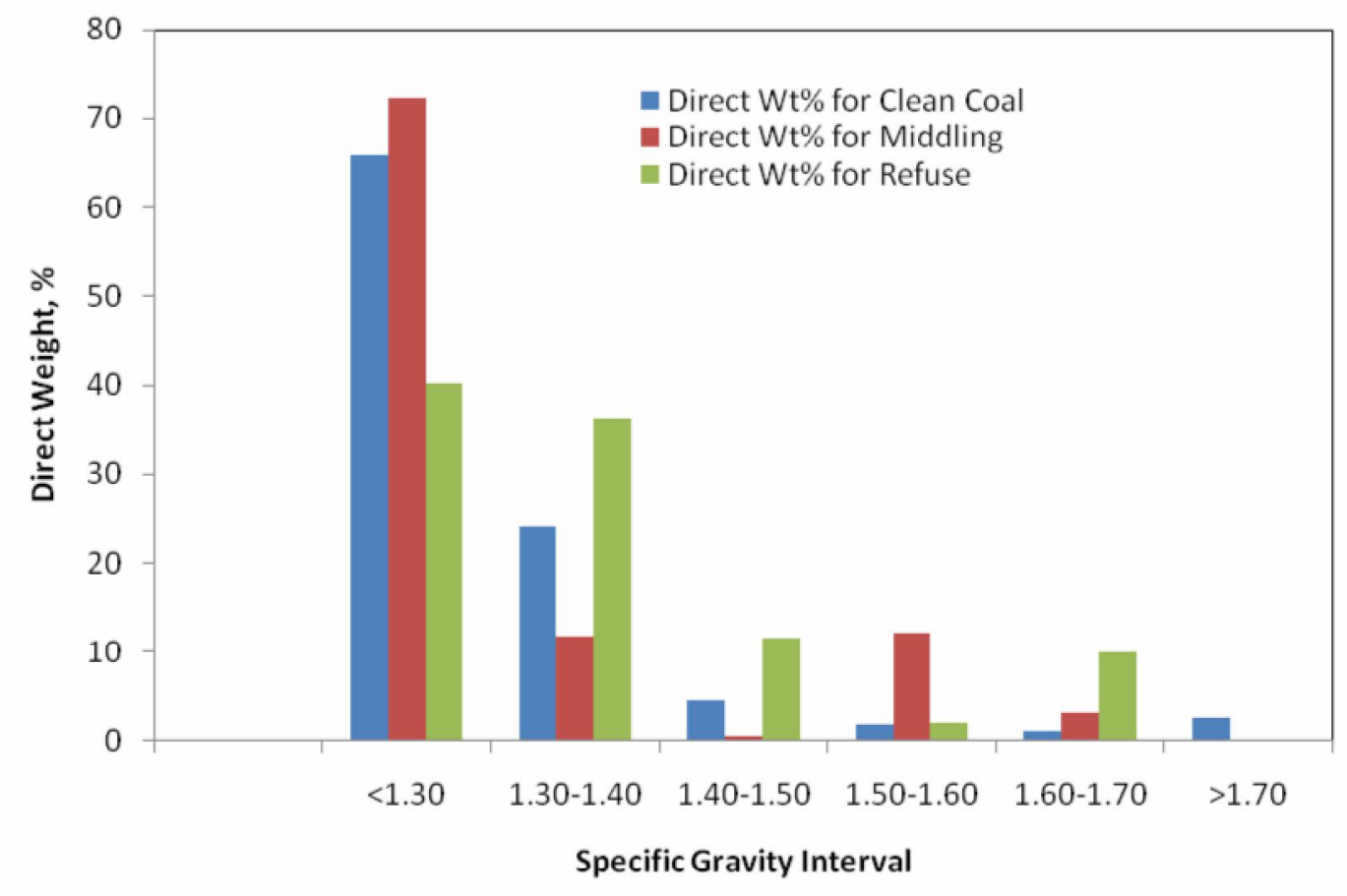

Figure 4.9 Direct weight percent for coarse spiral by specific gravity interval. 


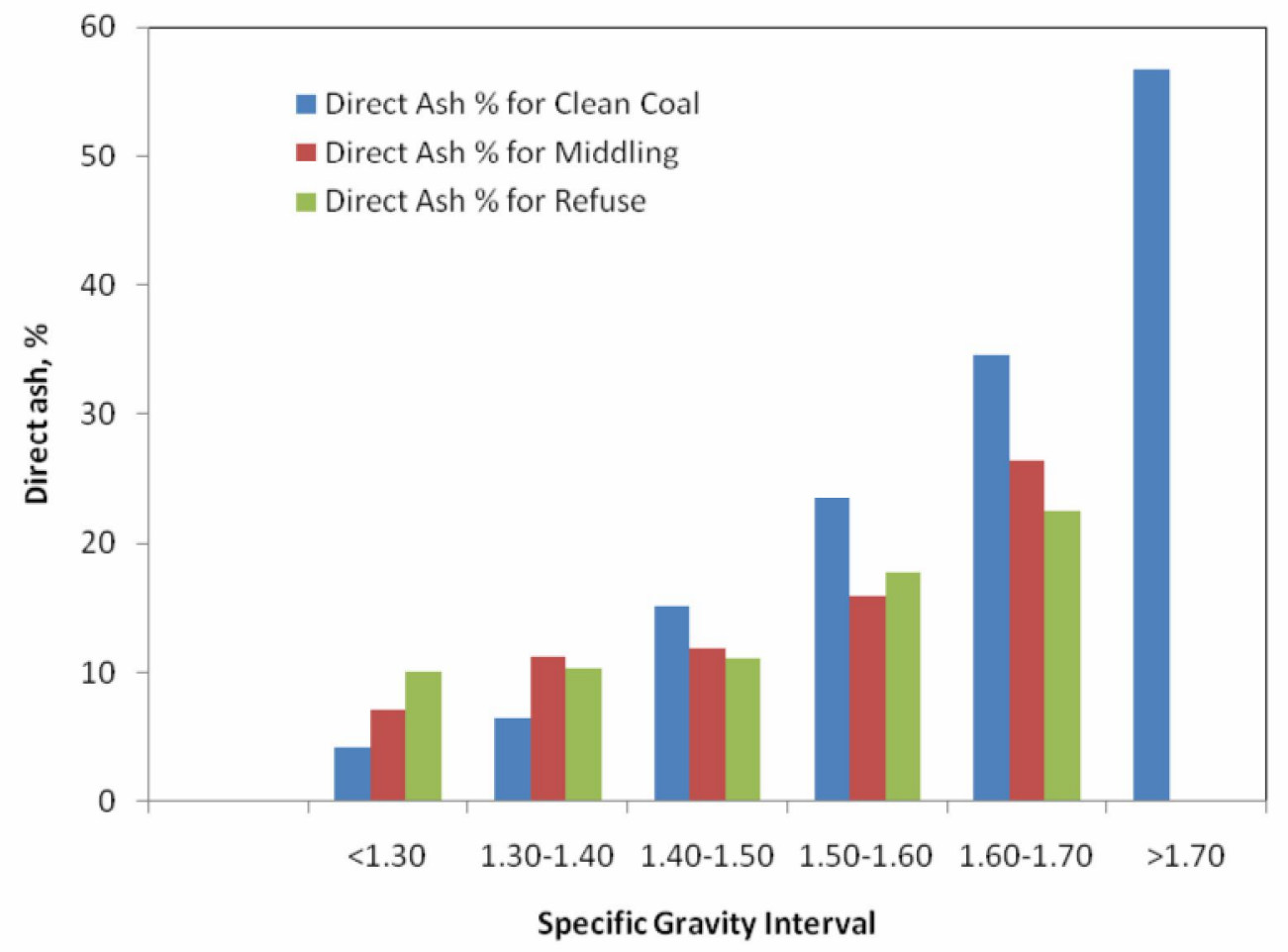

Figure 4.10 Direct ash percent for coarse spiral by specific gravity interval.

\subsubsection{Fractional recovery}

Presented in Figures 4.11 to 4.15 are the distribution curves for the coarse spiral clean coal and combined clean coal (clean coal + middlings) for the following size intervals: $+1.190 \mathrm{~mm},-0.190 \mathrm{~mm}+0.420 \mathrm{~mm},-0.420 \mathrm{~mm}+0.210 \mathrm{~mm},-0.210 \mathrm{~mm}+0.149 \mathrm{~mm}$, and $-0.149 \mathrm{~mm}$. Except for the size interval of $-0.190 \mathrm{~mm}+0.420 \mathrm{~mm}$ (Figure 4.12 ), the distribution factors for high specific gravity material $(>1.6)$ are lower than $20 \%$ (Figure $4.11,4.13,4.14$, and 4.15), indicating the misplacement of mineral contents to the clean coal is not significant as opposed to fine spiral. The distribution factors for the low 
specific gravity material $(<1.4)$ ranges from $50 \%$ to $90 \%$, illustrating the existence of various degrees of misplacement of clean coal to the refuse.

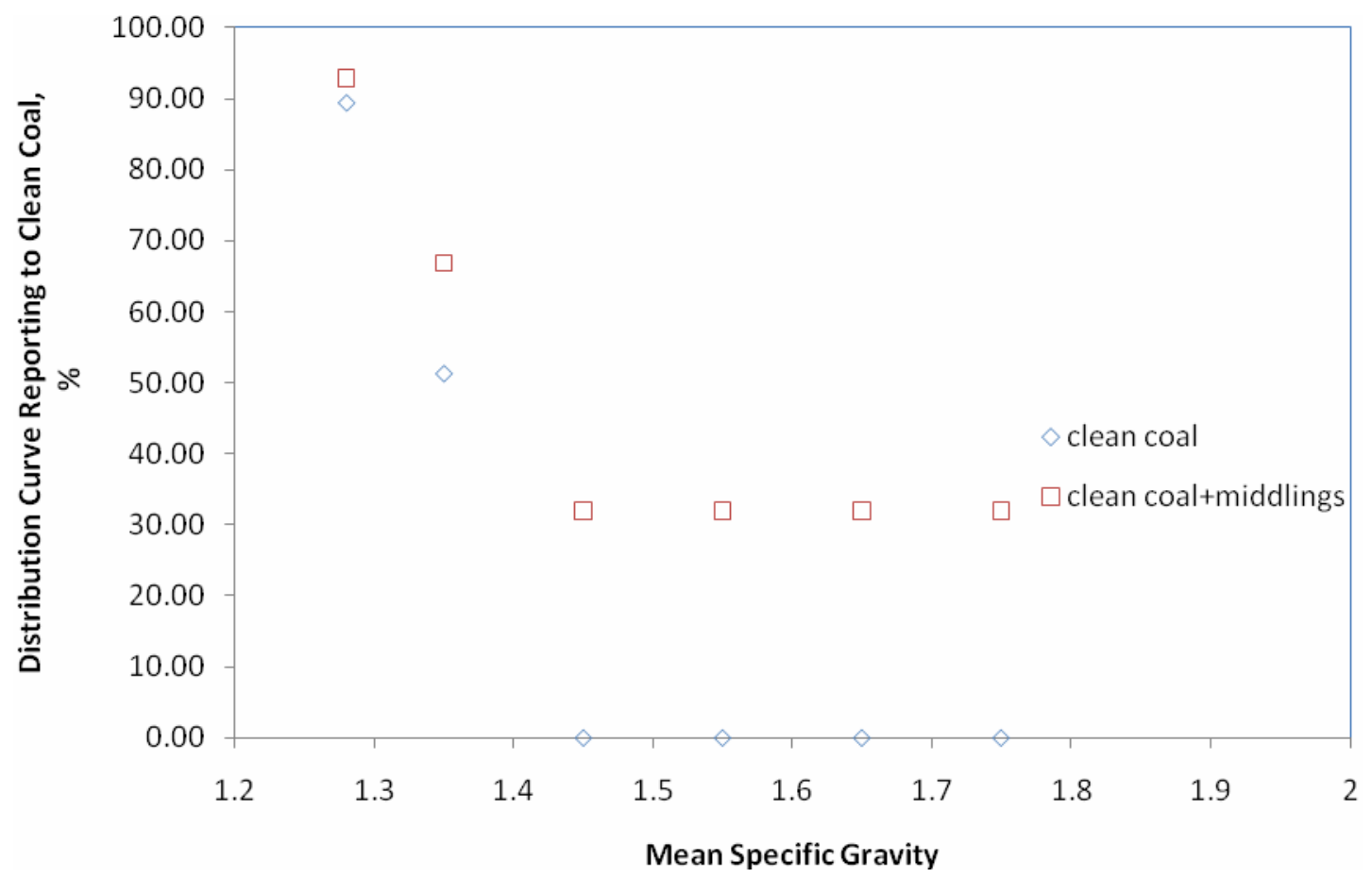

Figure 4.11 Distribution Curve for Coarse Spiral (Size Distribution: $+1.190 \mathrm{~mm}$ ). 


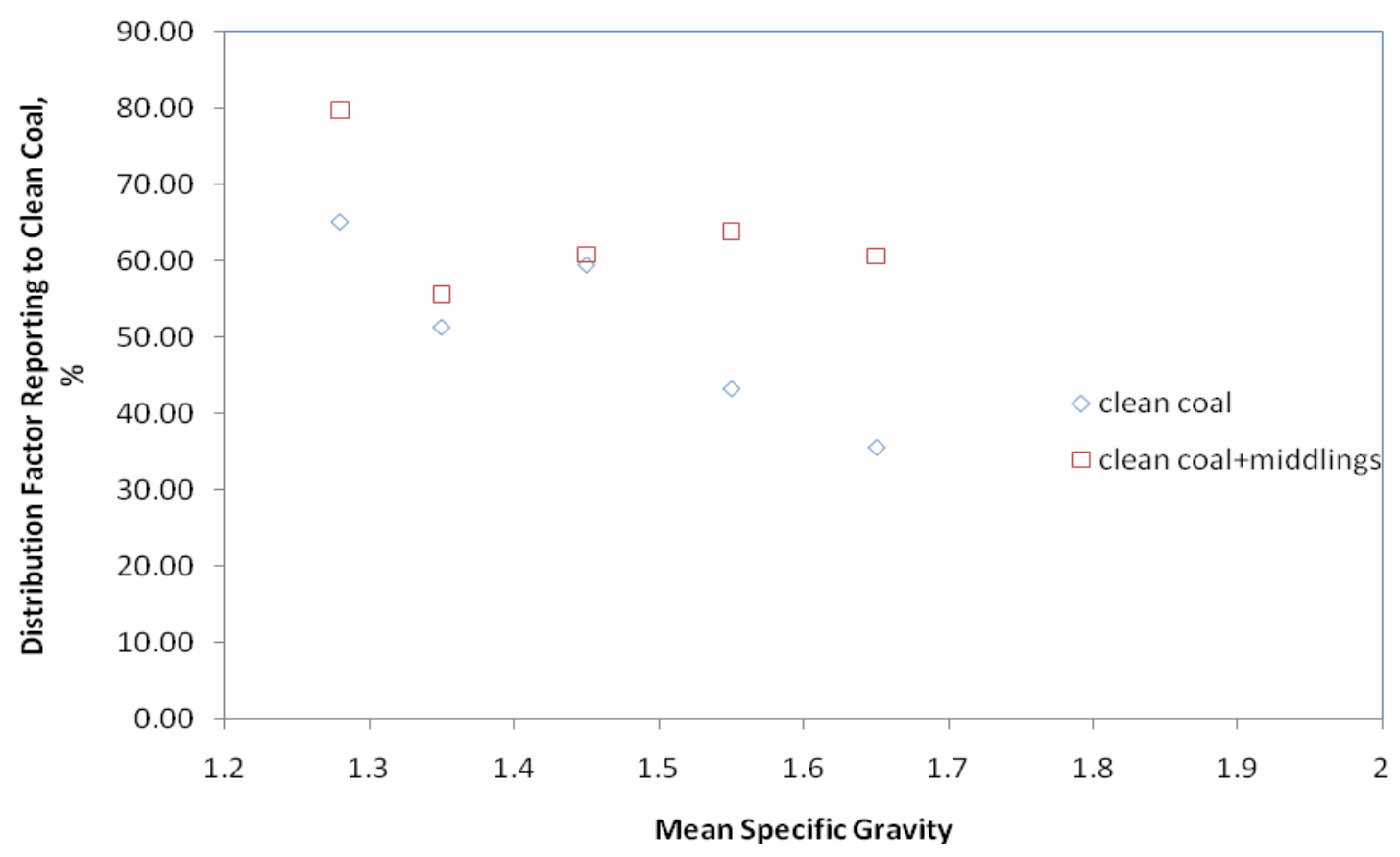

Figure 4.12 Distribution Curve for Coarse Spiral

(Size Distribution: $-0.190 \mathrm{~mm}+0.420 \mathrm{~mm}$ ).

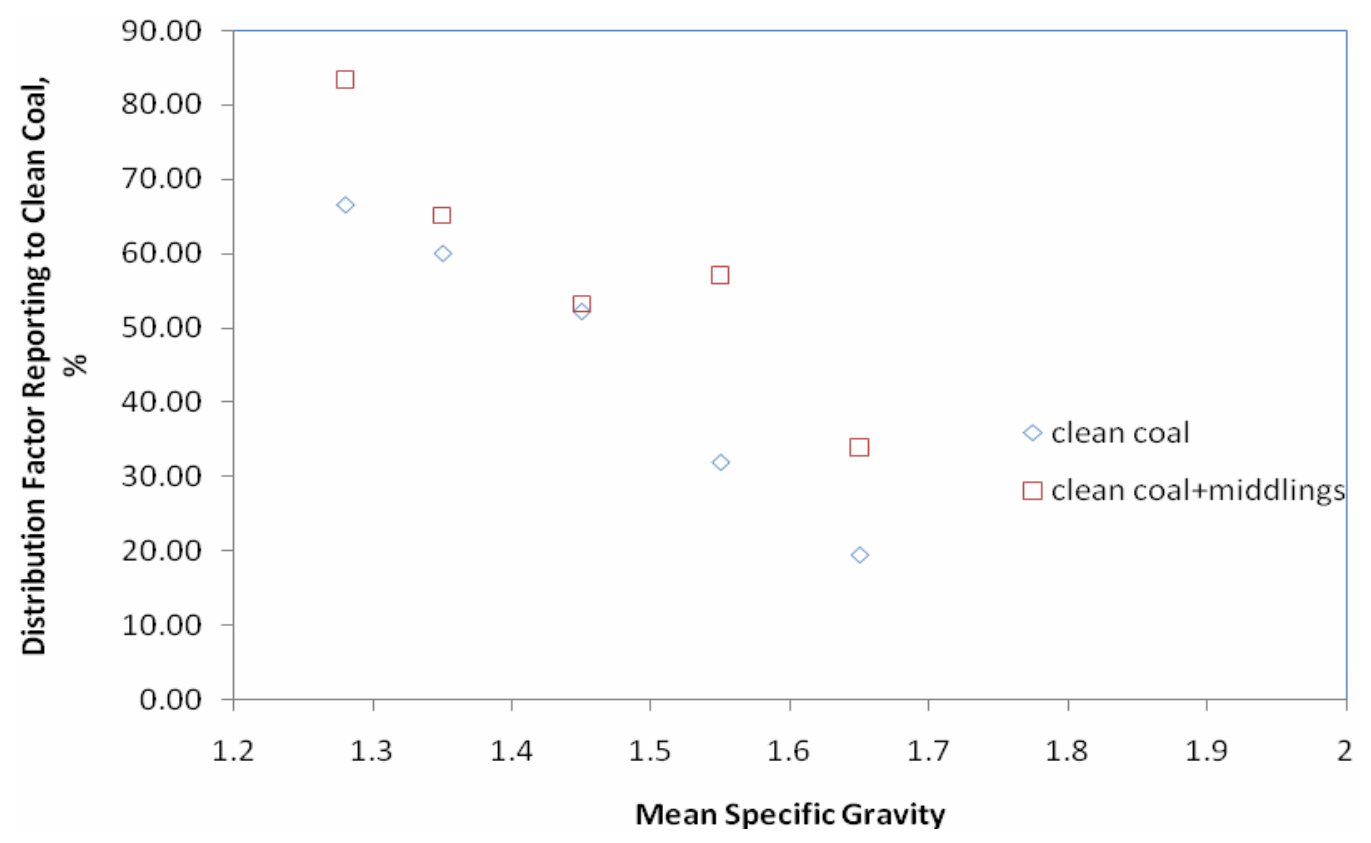

Figure 4.13 Distribution Curve for Coarse Spiral

(Size Distribution:-0.420mm+0.210mm). 


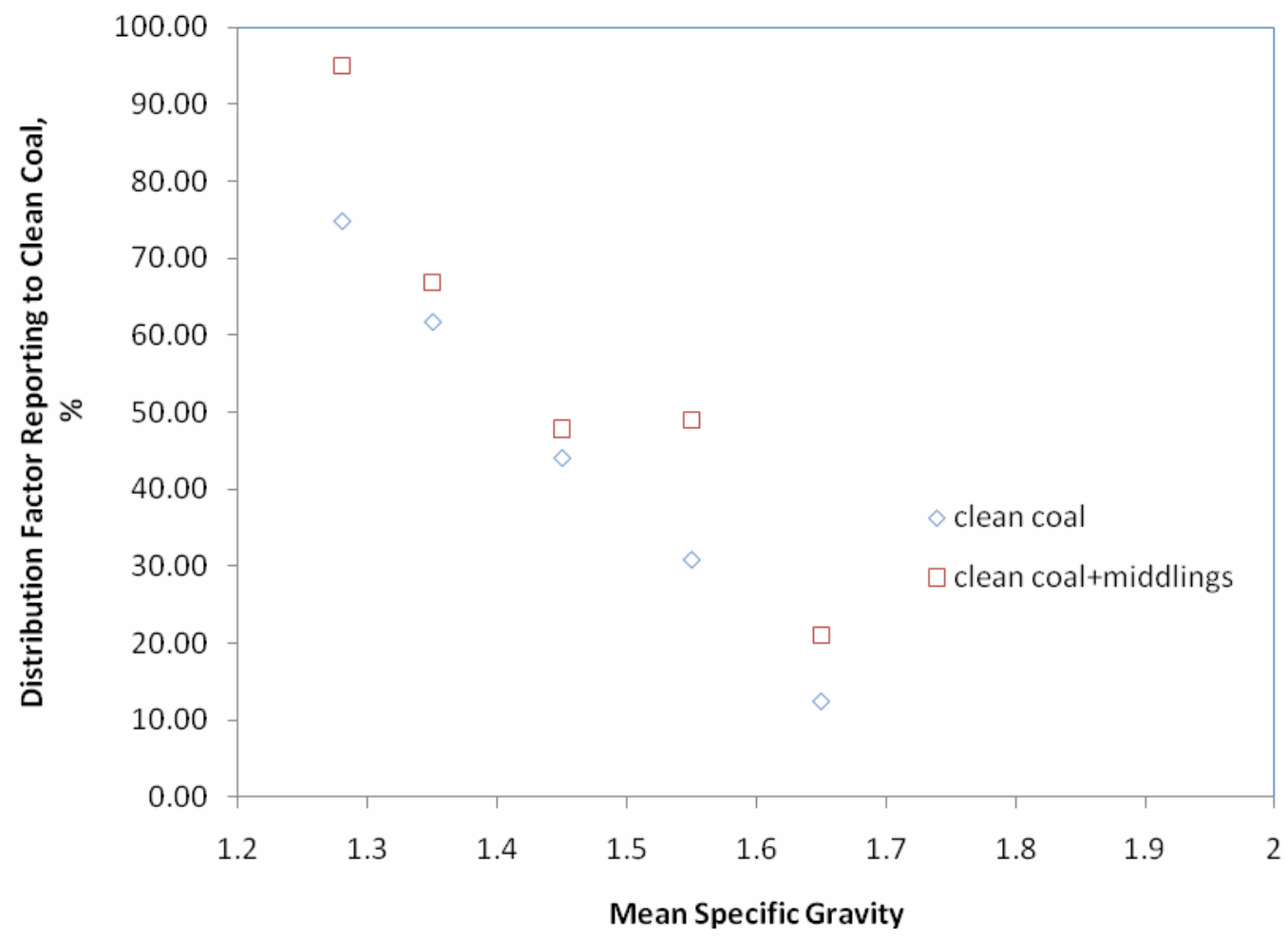

Figure 4.14 Distribution Curve for Coarse Spiral

(Size Distribution:-0.210mm+0.149mm). 


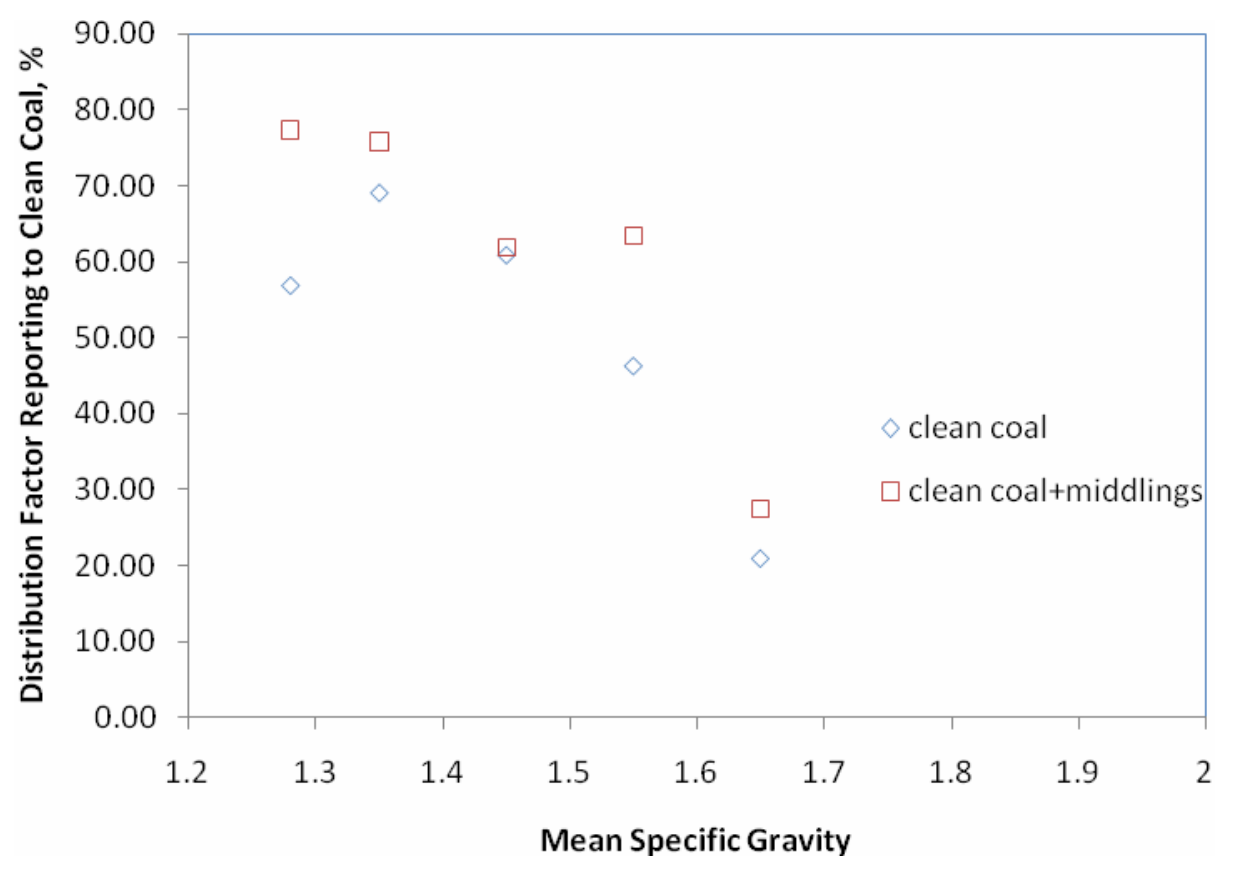

Figure 4.15 Distribution Curve for Coarse Spiral (Size

Distribution: $-0.149 \mathrm{~mm})$.

\subsection{Predicted Model for Fine and Coarse Spirals}

Since there has been a growing interest in using gravity concentration techniques to process fine coal, it is important to predict the performance in the operating conditions of the separator. The generation of partition curves can be an effective tool. The common industrial practice is to derive certain characteristic parameters directly from the curves. If these values are fitted to an appropriate mathematical function, then the derived parameters can be obtained using a parameter estimation technique. Thus, by analyzing the variation of these parameters with operating and design conditions, a valuable technique for studying separator performance cab established. The mathematical model 
used in the study is based upon the physics of the separation process, from which fractional recovery values can be obtained.

The mathematic model is the following (Klima and Luckie, 1989):

$$
K_{j i}=100 \frac{1}{1+\operatorname{Exp}\left[\left(\frac{1.098}{E p}\right)\left(S G-S G_{50}\right)\right]}
$$

Where, $E p=\frac{S G_{25}-S G_{75}}{2}$

$S G_{25}=$ density corresponding to 0.25 on the fractional recovery curve;

$S G_{75}=$ density corresponding to 0.75 on the fractional recovery curve;

$S G_{50}=$ the density corresponding to 0.5 on the fractional recovery curve (the equiprobable density because particles with this density have an equal probability of reporting to the product or refuse);

$K_{j i}=$ fractional recovery for spiral.

The fractional recovery curves fitted by the above model compared with the experiments curves for fine spiral composite size distribution $(-0.210 \mathrm{~mm})$ are showed in Figure 4.16. Similarly, the fractional recovery curves for coarse spiral composite size distribution $(-1.190 \mathrm{~mm})$ are presented in Figure 4.17. 


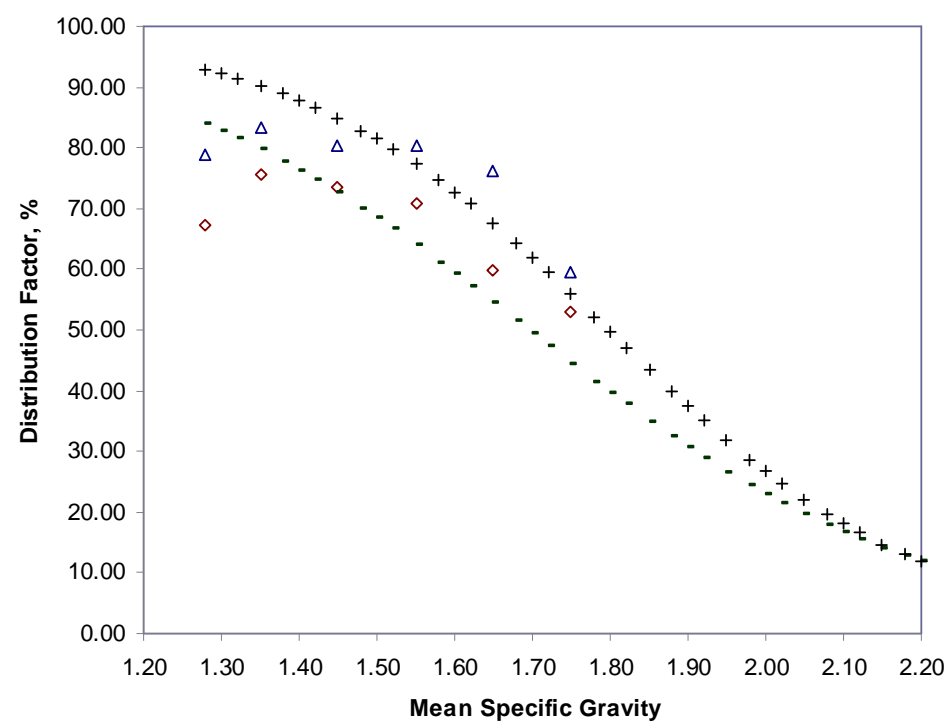

$\diamond$ clean coal (experiments)

- clean coal (predicted)

$\Delta$ clean coal+middlings (experiments)

+ clean coal+middlings (predicted)

Figure 4.16 Distribution curves compared between the experiments data and methemetic model for Fine Spiral (Composite Size Distribution).

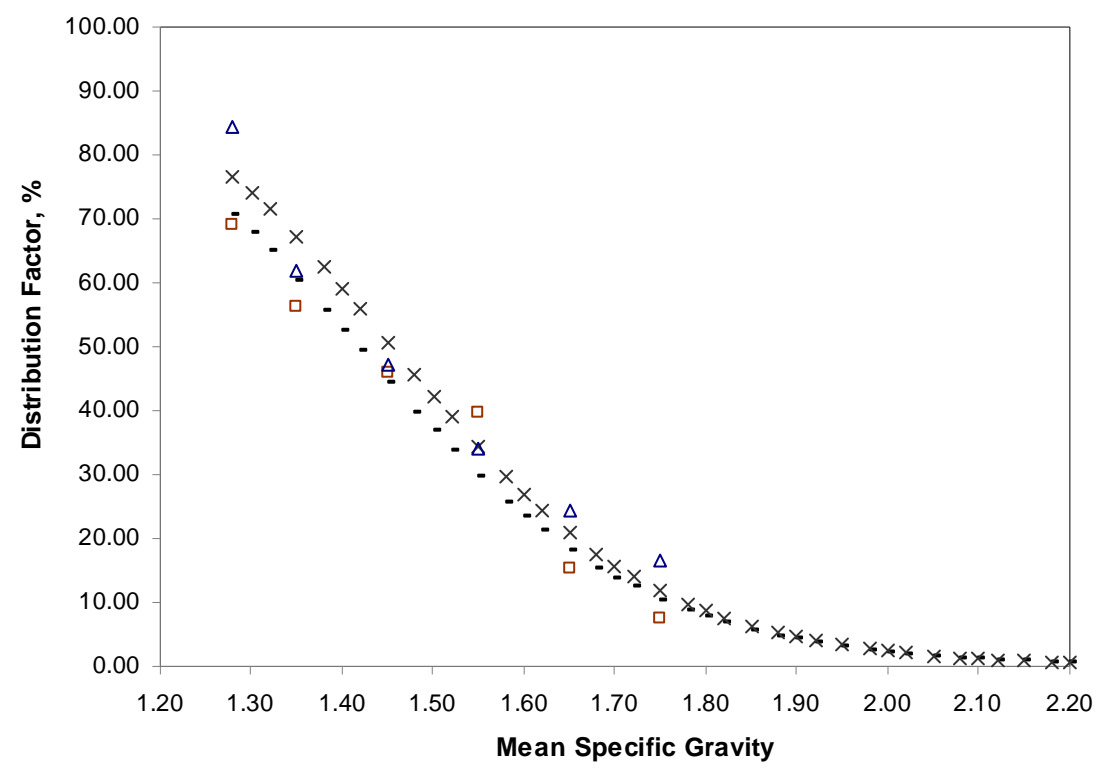

- clean coal (predicted)

$\times$ clean coal+middlings (predicted) $\checkmark$ clean coal (experiments) $\Delta$ clean coal+middlings (experiments)

Figure 4.17 Distribution curves compared between the experiments data and methemetic model for Coarse Spiral (Composite Size Distribution). 
For fine spiral, the distribution curves for composite size intervals predicted by the mathematical model reveals similar trend (Figure 4.16) as the curved obtained from the experiment (Figure 4.8). Meanwhile certain improvements are observed from the compares between model fitting curves and the experiments curves. For clean coal products, in a low specific gravity $(<1.4)$ the distribution factors get higher from $65 \sim 75 \%$ to $75 \% \sim 85 \%$, indicating that a portion of coarse clean coal is entrained into the refuse. The distribution factor of high specific gravity material $(>1.7)$ is around $40 \sim 50 \%$ same as the curves from the experiments demonstrating that significant amount of fine mineral particles (slime) is misplaced into clean coal with slurry flow. As expected, when the middlings stream is combined with clean coal, there is a slight decrease in the amount of lost clean coal and the amount of lost high density material (mineral contents). The distribution factors for light materials (specific gravity $<1.4)$ and heavy materials $(>1.6)$ are $85 \sim 95 \%$ and $60 \sim 65 \%$, respectively, illustrating the existence of misplaced clean coal and mineral contents.

Presented in Figures 4.17 are the distribution curves compared between the experimental data and the fitting model for the coarse spiral clean coal and combined clean coal (clean coal + middlings) for the composite size intervals. The model fitting curves improved the distribution factor reporting to clean coal higher than the experiments data curves. And the distribution factors for high specific gravity material (>1.6) are lower than $20 \%$ indicating the misplacement of mineral contents to the clean coal is not significant as opposed to fine spiral. The distribution factors for the low specific gravity material $(<1.4)$ ranges from $50 \%$ to $90 \%$, illustrating the existence of various degrees of misplacement of clean coal to the refuse. 
Table 4.3 Summary of the fine and coarse spiral parameters.

\begin{tabular}{cccccc}
\hline & & \multicolumn{2}{c}{ Clean Coal Only } & \multicolumn{2}{c}{ Clean Coal and Middlings } \\
& & Experiment & Model Predicted & Experiment & Model Predicted \\
\hline $\begin{array}{c}\text { Fine } \\
\text { Spiral }\end{array}$ & Ep & 0.35 & 0.27 & 0.33 & 0.22 \\
& SG50 & 1.80 & 1.70 & 1.83 & 1.80 \\
Coarse & Ep & 0.20 & 0.17 & 0.21 & 0.16 \\
Spiral & SG50 & 1.45 & 1.42 & 1.46 & 1.45 \\
\hline
\end{tabular}

Table 4.3 represents the summary of the fine and coarse spiral parameters of Ep and SG50 values. When high density refuse enters the clean coal stream, the SG50 increases. A lower Ep means there was a bette separation of clean coal and refuse material. An ideal separation would give and Ep eaual to zero, in which case $100 \%$ of the coal with specific gravity less than SG50 would report to the clean coal stream and $100 \%$ of the coal with specific gravity greater than SG50 would report to the refuse stream. The parameters (Ep, SG50) predicted from the modle fitting were calculated using the solver function in Excel. This was done by minimizing the sum of squares of the errors for a given size interval.

For fine spiral, clean coal combined with middlings products yield was higher than the clean coal products, therefore the SG50 was higher. Consequently Ep was lower. Coarse sqiral had lower SG50 and Ep values than fine spiral. The low SG50 resulted in a low amount of low density material. This showed that more material could have been allowed to enter the plant clean coal stream. All SG50 and Ep values from experiments were higher than from the model predicted. It showed a lot of improvments needed to do by changing the spiral operation conditions. 


\section{Chapter 5}

\section{Conclusions and Recommendations}

Wet coal samples were collected from the fine spirals and coarse spirals in Shade Coal Preparation Plant and washability tests were carried out to evaluate the effectiveness of spirals in cleaning fine and coarse coal. Based on the results of this study, the following conclusions can be drawn:

1. The fine spiral is able to recovery $65.5 \%$ of the deslime hydrocyclone underflow as clean coal with an ash content of $8.26 \%$.

2. The ash contents for the refuse and middlings from the fine spiral are almost the same, which could be caused by the improper position of splitter.

3. For the fine spiral, a portion of coarse clean coal $(>0.074 \mathrm{~mm})$ is entrained into the refuse, and significant amount of fine mineral particles (slime) are misplaced into clean coal.

4. The coarse spiral recovers $61.5 \%$ of the 15 -inch hydrocyclone underflow as clean coal with an ash content of $7.26 \%$.

5. The light material (specific gravity $<1.3$ ) constitutes $73 \%$ of the middlings, and $67 \%$ of clean coal of the coarse spiral.

6. For the coarse spiral, the misplacement of mineral contents to the clean coal is not significant as opposed to fine spiral. There are various degrees of misplacement of clean coal to the refuse of the coarse spiral. 
Based on the conclusions above, the following recommendations are made:

1. For the fine spiral, the middlings should be mixed with the refuse, instead of mixing with clean coal as final product. The position of splitter between the middlings and the refuse should be adjusted towards the outer rim of the spiral to reduce the ash content in the middlings.

2. For the coarse spiral, the middlings should be combined with clean coal to obtain combined clean coal with satisfactory ash content. If low ash content is desired, the position of splitter between middlings and the refuse can be adjusted towards the outer rim.

3. To fully realize the great potentials of spirals in coarse and fine coal cleaning, optimization of operational conditions (feed rate, slurry solids content, and position of splitters etc.) should be considered to minimize the existence of misplaced materials to the clean coal or the refuse. 


\section{References}

Bethell, P.J., and Arnold, B.J. (2003). “ Comparing a two-stage spiral to two stages of spirals for fine coal preparation ", Advances in Gravity Concentration, by Honaker, R.Q. and Forrest, W.R. (Ed), SME, Littleton, CO, pp. 107-114.

Burt, R.O., (1984) Gravity Concentration Technology, Elsevier. Amsterdam, pp. 261-287. DTI, (2001). Coal Preparation, Technology Status Report 015, Department of Trade and Industry, UK.

Holland-Batt, A.B., (1995), “ The Dynamics of Sluice and Spiral Separations ”, Minerals Engineering, Vol. 8, No. 1-2, pp. 3-21.

Holland-Batt, A.B. (1992) A Study of the Potential for Improved Separation of Fine Particles by Use of Rotating Spirals, Minerals Engineering, 5(10-12), 1099-1112.

Honaker, R.Q., and Mohanty, M.K., (1996) Enhanced column flotation performance for fine coal cleaning, Minerals Engineering, Vol 9, No. 9, pp. 931-945.

Kapur, P.C., Meloy, T.P. (1998). Spirals observed, International Journal of Mineral Processing, 53, 15-28.

Klima, M. S. and Luckie, P. T., 1989, 'Application of an Unsteady-State Pulp-Partition Model to Dense-Medium Separations", Coal Preparation, Vol. 6 No. 3, pp. 227-240.

Kohmuench, J.N. (2000). Improving efficiencies in water-based separators using mathematical analysis tools, Dissertation, Virginia Polytechnic Institute and State University. 
Kohmuench, J.N., Mankosa, M.J., Honaker, R.Q., Bratton, R.C. (2006) Applications of the CrossFlow teeter-bed separator in the U.S. coal industry, Minerals and Metallurgical Processing, 23(4), 187-195.

Larry, A.W., Daniel, S.P., (2006) System and Method for Beneficiating Ultra-fine Raw Coal with Spiral Concentrators, United States Patent Application Publication, Sedgman LLC, Pittsburgh, PA, Pub.No.: US 2006/0180525 A1.

Luttrell, G.H. (2003) Dense separation: are we really making use of existing process engineering knowledge? Advances in Gravity Concentration, edited by Honaker, R.Q. and Forrest, W.R. (Ed), SME, Littleton, CO.

MacHunter, D.M., Richards, R.G., Palmer, M.K. (2003) Improved gravity separation systems utilizing spiral separaters incorporating new design parameters and features, Heavy Minerals 2003, Johannesburg, South African Institute of Mining and Metallurgy, 131-138.

MacNamara, L., Addison, F., Miles, N.J., Bethell, P., and Davies, P. (1995) The Application of New Configurations of Coal Spirals, Proceedings of 12th International Coal Preparation Conference and Exhibit, Lexington, Kentucky, May 2-4, 1995.

MacNamara, L., Toney T.A., Moorhead, R.G., Miles, N.J., Bethell, P., and Everitt, B. (1996) On site testing of the compound spiral, Proceedings of 13th International Coal Preparation Conference and Exhibit, Lexington, Kentucky, April 30-May 2, 1996.

Mikhail, M.W., Salama, A.I.A., Parsons, I.S., Humeniuk, O.E. (1998) Evalution and application of spirals and water-only cyclones in cleaning fine coal, Coal Preparation, $6,53-78$. 
Palowitch, E.R., Deurbrouck, A.W., Parsons, T.H. (1991) Wet fine particle concentration, Section 2, Hydraulic Concentration, in: Coal Preparation, Leonard, J.W. (Ed.), SME, Littleton, CO, 435-449.

R. Q. Honaker, M. Jain, B. K. Parekh, M. Saracoglu (2007), Ultrafine Coal Cleaning Using Spiral Concentrators, Minerals Engineering, Vol. 20, No. 14, pp. 1315-1319.

Walsh, D.E., Kelly, E.G. (1992) An investigation of the performance of a spiral using radioactive gold tracers, Minerals and Metallurgical Processing, 9(3), 105-109.

Weldon, B. (1997). Fine coal beneficiation: spiral separators in the Australian industry, The Australia Coal Review, 1997, 25-28.

Weldon, W.S., MacHunter, R.M.G., (1997) Recent advances in coal spiral development, SME Annual Meeting, Denver, Colorado, Preprint No. 97-82, Feb. 24-27, 1997.

Wills, B.A. (1992). Mineral Processing Technology, 5th Edition, 1992, 430-433. 
APPENDIX A

\section{OPERATING PROCEDURES}




\section{FLOAT-SINK ANALYSIS PROCEDURE}

1. All the samples are de-canned and dried for float-sink analysis.

2. Combining the heavy liquids (LMT) with distilled water in $4000 \mathrm{ml}$ beaker to create the following densities: $1.30,1.40,1.50,1.60,1.70$ and 1.80. Checking each density by using a hydrometer prior to the analysis.

3. Placing each representative coal sample LMT in weights that would yield a solid concentration of no more than $5 \%$ by volume.

4. Under the ventilation hood, placing the pre-weighed coal samples in a $4000 \mathrm{ml}$ beaker. Manually stirring the liquid to ensure that all of the coal is wetted.

5. Using a wash bottle to wash the stirring rod and the inside walls of the beaker.

6. Covering the beaker with paraffin to minimize evaporation and leaving solids to sit for at least 12 hours.

7. After the separation is complete, using a vacuum system to siphon off the layer of the floating coal. Placing a float in a filter labeled float by using a wire mesh strainer and pouring the materials left in the beaker into the other filters labeled sink. Draining the heavy liquid (LMT) and returning to the appropriate bottle. Drying both the float and the sink products in an oven to ensure that all the surface liquid is dry.

8. After 12 hours in the oven, taking the coal out of the oven and weighing, bagging, saving for the subsequent analysis. 


\section{Wet Sieving Procedure}

1. To prepare for a wet sieve test, dry the sample to a constant mass at the room temperature.

2. Weight the sample to the nearest $0.1 \mathrm{~g}$ and mix with water thoroughly.

3. When the material readily mixes with water, place the sample on the coarsest sieve, and wash it back and forth with a gentle stream from a hose.

4. When the water passing through the sieve is clear, place the sample passed through the coarsest sieve on the second coarser sieve until pass through the finest sieve.

5. Dry the sieve containing the residue in an oven at $40^{\circ} \mathrm{C}$ for 12 hours.

6. Weight the sample from each siever and bag and label. 


\section{Ash Analysis Procedure}

1. Transfer 1 gram of coal sample to a weighed capsule and cover quickly;

2. Place the capsule in a cold furnace and heat gradually at a rate that the temperature reaches $450^{\circ} \mathrm{C}$ to $500^{\circ} \mathrm{C}$ in one hour;

3. Continue heating to $700^{\circ} \mathrm{C}$ to $750{ }^{\circ} \mathrm{C}$ is reached by the end of the second hour;

4. Continue ash for additional two hours;

5. Remove the capsule from the muffle, place the capsule aside to cool. 
APPENDIX B

\section{DESLIMED BITUMINOUS COAL TEST RESULTS}


Washability Analysis of Fine Spiral Medium Coal

\begin{tabular}{|l|r|r|r|r|r|}
\hline \multirow{2}{*}{$\begin{array}{c}\text { Specific } \\
\text { Gravity } \\
\text { Interval }\end{array}$} & \multicolumn{3}{|c|}{ Direct } & \multicolumn{2}{c|}{ Cummulate } \\
\cline { 2 - 6 } & $\mathrm{Wt}(\mathrm{g})$ & \multicolumn{1}{c|}{$\mathrm{Wt} \%$} & \multicolumn{1}{c|}{ Ash\% } & \multicolumn{1}{c|}{$\mathrm{Wt} \%$} & \multicolumn{1}{c|}{ Ash\% } \\
\hline$<1.30$ & 193.63 & 47.59 & 18.29 & 47.59 & 18.29 \\
\hline $1.30-1.40$ & 29.37 & 7.22 & 6.05 & 54.81 & 16.68 \\
\hline $1.40-1.50$ & 39.47 & 9.70 & 8.88 & 64.51 & 15.51 \\
\hline $1.50-1.60$ & 51.45 & 12.65 & 12.05 & 77.15 & 14.94 \\
\hline $1.60-1.70$ & 21.9 & 5.38 & 14.10 & 82.54 & 14.88 \\
\hline$>1.70$ & 71.06 & 17.46 & 22.89 & 100.00 & 16.28 \\
\hline & 406.88 & 100.00 & 16.28 & & \\
\hline
\end{tabular}

\section{Washability Analysis of Fine Spiral Refuse Coal}

\begin{tabular}{|l|r|r|r|r|r|}
\hline \multirow{2}{*}{$\begin{array}{c}\text { Specific Gravity } \\
\text { Interval }\end{array}$} & \multicolumn{3}{|c|}{ Direct } & \multicolumn{2}{c|}{ Cummulate } \\
\cline { 2 - 6 } & Wt $(\mathrm{g})$ & \multicolumn{1}{c|}{ Wt $\%$} & \multicolumn{1}{c|}{ Ash\% } & \multicolumn{1}{c|}{ Wt $\%$} & \multicolumn{1}{c|}{ Ash\% } \\
\hline$<1.30$ & 114.36 & 32.54 & 11.48 & 32.54 & 11.48 \\
\hline $1.30-1.40$ & 20.48 & 5.83 & 7.47 & 38.36 & 10.87 \\
\hline $1.40-1.50$ & 35.48 & 10.09 & 7.28 & 48.46 & 10.12 \\
\hline $1.50-1.60$ & 33.49 & 9.53 & 8.97 & 57.98 & 9.93 \\
\hline $1.60-1.70$ & 9.97 & 2.84 & 11.45 & 60.82 & 10.00 \\
\hline $1.70-1.80$ & 137.71 & 39.18 & 15.76 & 100.00 & 12.26 \\
\hline$>1.80$ & 0.00 & 0.00 & 43.48 & & 12.26 \\
\hline & 351.49 & 100.00 & 12.26 & & \\
\hline
\end{tabular}


Ash Analysis of Fine Spiral Clean Coal by Size Interval

$$
\text { S.G. }<1.30
$$

\begin{tabular}{crrrr}
\hline Size Interval & \multicolumn{2}{c}{ Direct } & \multicolumn{2}{c}{ Cumulative Float } \\
\hline Mesh & Weight \% & \% Ash & Weight \% & $\%$ Ash \\
\hline 70 & 41.12 & 4.79 & 41.12 & 4.79 \\
$70 \times 100$ & 6.72 & 3.62 & 47.85 & 4.63 \\
$100 \times 200$ & 17.56 & 4.23 & 65.41 & 4.52 \\
$200 \times 325$ & 3.93 & 7.26 & 69.34 & 4.68 \\
-325 & 30.66 & 10.06 & 100.00 & 6.33 \\
& 100.00 & 6.33 & & \\
\hline
\end{tabular}

Ash Analysis of Fine Spiral Clean Coal by Size Interval

$$
1.30<\text { S.G. }<1.40
$$

\begin{tabular}{crrrr}
\hline Size Interval & \multicolumn{3}{c}{ Direct } & \multicolumn{2}{c}{ Cumulative Float } \\
\hline Mesh & Weight $\%$ & \% Ash & Weight \% & $\%$ Ash \\
\hline 70 & 24.04 & 5.19 & 24.04 & 5.19 \\
$70 \times 100$ & 12.55 & 3.47 & 36.59 & 4.60 \\
$100 \times 200$ & 53.74 & 3.56 & 90.32 & 3.98 \\
$200 \times 325$ & 9.68 & 4.20 & 100.00 & 4.00 \\
-325 & 0.00 & 0.00 & 100.00 & 4.00 \\
& 100.00 & 4.00 & & \\
\hline
\end{tabular}


Ash Analysis of Fine Spiral Clean Coal by Size Interval

$$
1.40<\text { S.G. }<1.50
$$

\begin{tabular}{crrrr}
\hline Size Interval & \multicolumn{2}{c}{ Direct } & \multicolumn{2}{c}{ Cumulative Float } \\
\hline Mesh & Weight \% & \% Ash & Weight \% & $\%$ Ash \\
\hline 70 & 7.76 & 11.86 & 7.76 & 11.86 \\
$70 \times 100$ & 7.24 & 5.11 & 14.99 & 8.60 \\
$100 \times 200$ & 33.73 & 4.86 & 48.72 & 6.01 \\
$200 \times 325$ & 4.19 & 5.22 & 52.91 & 5.95 \\
-325 & 47.09 & 7.73 & 100.00 & 6.79 \\
& 100.00 & 6.79 & & \\
\hline
\end{tabular}

Ash Analysis of Fine Spiral Clean Coal by Size Interval

$$
1.50<\text { S.G. }<1.60
$$

\begin{tabular}{crrrr}
\hline Size Interval & \multicolumn{2}{c}{ Direct } & \multicolumn{2}{c}{ Cumulative Float } \\
\hline Mesh & Weight \% & \% Ash & Weight \% & $\%$ Ash \\
\hline 70 & 9.40 & 13.91 & 9.40 & 13.91 \\
$70 \times 100$ & 4.78 & 7.82 & 14.18 & 11.85 \\
$100 \times 200$ & 48.46 & 6.43 & 62.64 & 7.66 \\
$200 \times 325$ & 16.88 & 7.05 & 79.51 & 7.53 \\
-325 & 20.49 & 10.86 & 100.00 & 8.21 \\
& 100.00 & 8.21 & & \\
\hline
\end{tabular}


Ash Analysis of Fine Spiral Clean Coal by Size Interval

$$
1.60<\text { S.G. }<1.70
$$

\begin{tabular}{crrrr}
\hline Size Interval & \multicolumn{2}{c}{ Direct } & \multicolumn{2}{c}{ Cumulative Float } \\
\hline Mesh & Weight $\%$ & \% Ash & Weight \% & $\%$ Ash \\
\hline 70 & 0.00 & 11.99 & 0.00 & 11.99 \\
$70 \times 100$ & 9.40 & 7.87 & 9.40 & 7.87 \\
$100 \times 200$ & 10.96 & 9.02 & 20.36 & 8.49 \\
$200 \times 325$ & 11.82 & 11.05 & 32.18 & 9.43 \\
-325 & 67.82 & 10.77 & 100.00 & 10.34 \\
& 100.00 & 10.34 & & \\
\hline
\end{tabular}

Ash Analysis of Fine Spiral Clean Coal by Size Interval

$$
\text { S.G. }>1.70
$$

\begin{tabular}{crrrr}
\hline Size Interval & \multicolumn{2}{c}{ Direct } & \multicolumn{2}{c}{ Cumulative Float } \\
\hline Mesh & Weight $\%$ & \% Ash & Weight \% & $\%$ Ash \\
\hline 70 & 0.00 & 0.00 & 0.00 & 0.00 \\
$70 \times 100$ & 19.36 & 8.00 & 19.36 & 8.00 \\
$100 \times 200$ & 7.66 & 9.32 & 27.02 & 8.37 \\
$200 \times 325$ & 9.45 & 11.56 & 36.47 & 9.20 \\
-325 & 63.53 & 18.65 & 100.00 & 15.20 \\
& 100.00 & 15.20 & & \\
\hline
\end{tabular}


Float and Sink Analysis of Fine Spiral Clean Coal

+ No.70 mesh

\begin{tabular}{lrrrr}
\hline \multirow{2}{*}{$\begin{array}{c}\text { Specific Gravity } \\
\text { Interval }\end{array}$} & \multicolumn{2}{c}{ Direct } & \multicolumn{2}{c}{ Cumulative Float } \\
\cline { 2 - 5 }$<1.30$ & Weight $\%$ & \% Ash & Weight \% & $\%$ Ash \\
\hline $1.30-1.40$ & 11.55 & 5.19 & 77.23 & 4.79 \\
$1.40-1.50$ & 5.33 & 11.86 & 88.78 & 4.84 \\
$1.50-1.60$ & 5.89 & 13.91 & 100.00 & 5.75 \\
$1.60-1.70$ & 0.00 & 11.99 & 100.00 & 5.75 \\
$>1.70$ & 0.00 & 0.00 & 100.00 & 5.75 \\
& 100.00 & 5.75 & & \\
\hline
\end{tabular}

Float and Sink Analysis of Fine Spiral Clean Coal

- No.70+ No.100 mesh

\begin{tabular}{lrrrr}
\hline \multirow{2}{*}{$\begin{array}{c}\text { Specific Gravity } \\
\text { Interval }\end{array}$} & \multicolumn{2}{c}{ Direct } & \multicolumn{3}{c}{ Cumulative Float } \\
\cline { 2 - 5 }$<1.30$ & 27.52 & 6.72 & 27.52 & 6.72 \\
$1.30-1.40$ & 13.15 & 3.47 & 40.66 & 5.67 \\
$1.40-1.50$ & 10.84 & 5.11 & 51.50 & 5.55 \\
$1.50-1.60$ & 6.53 & 7.82 & 58.03 & 5.81 \\
$1.60-1.70$ & 2.67 & 7.87 & 60.70 & 5.90 \\
$>1.70$ & 39.30 & 8.00 & 100.00 & 6.72 \\
& 100.00 & 6.72 & & \\
\hline
\end{tabular}


Float and Sink Analysis of Fine Spiral Clean Coal

- No.100+ No.200 mesh

\begin{tabular}{lrrrr}
\hline \multirow{2}{*}{$\begin{array}{c}\text { Specific Gravity } \\
\text { Interval }\end{array}$} & \multicolumn{2}{c}{ Direct } & \multicolumn{2}{c}{ Cumulative Float } \\
\cline { 2 - 5 }$<1.30$ & 27.28 & 4.23 & 27.28 & 4.23 \\
$1.30-1.40$ & 21.36 & 3.56 & 48.64 & 3.94 \\
$1.40-1.50$ & 19.16 & 4.86 & 67.80 & 4.20 \\
$1.50-1.60$ & 25.12 & 6.43 & 92.92 & 4.80 \\
$1.60-1.70$ & 1.18 & 9.02 & 94.10 & 4.85 \\
$>1.70$ & 5.90 & 9.32 & 100.00 & 5.12 \\
& 100.00 & 5.12 & & \\
\hline
\end{tabular}

Float and Sink Analysis of Fine Spiral Clean Coal

- No.200+ No.325 mesh

\begin{tabular}{lrrrr}
\hline \multirow{2}{*}{$\begin{array}{c}\text { Specific Gravity } \\
\text { Interval }\end{array}$} & \multicolumn{2}{c}{ Direct } & \multicolumn{2}{c}{ Cumulative Float } \\
\cline { 2 - 5 }$<1.30$ & 20.60 & 7.26 & 20.60 & 7.26 \\
$1.30-1.40$ & 12.98 & 4.20 & 33.58 & 6.08 \\
$1.40-1.50$ & 8.03 & 5.22 & 41.62 & 5.91 \\
$1.50-1.60$ & 29.53 & 7.05 & 71.15 & 6.38 \\
$1.60-1.70$ & 4.29 & 11.05 & 75.44 & 6.65 \\
$>1.70$ & 24.56 & 11.56 & 100.00 & 7.86 \\
& 100.00 & 7.86 & & \\
\hline
\end{tabular}


Float and Sink Analysis of Fine Spiral Clean Coal

- No.325 mesh

\begin{tabular}{lrrrr}
\hline \multirow{2}{*}{$\begin{array}{c}\text { Specific Gravity } \\
\text { Interval }\end{array}$} & \multicolumn{2}{c}{ Direct } & \multicolumn{2}{c}{ Cumulative Float } \\
\cline { 2 - 5 }$<1.30$ & 33.73 & 10.06 & 33.73 & 10.06 \\
$1.30-1.40$ & 0.00 & 0.00 & 33.73 & 10.06 \\
$1.40-1.50$ & 18.94 & 7.73 & 52.67 & 9.22 \\
$1.50-1.60$ & 7.52 & 10.86 & 60.19 & 9.43 \\
$1.60-1.70$ & 5.17 & 10.77 & 65.36 & 9.53 \\
$>1.70$ & 34.64 & 18.65 & 100.00 & 12.69 \\
& 100.00 & 12.69 & & \\
\hline
\end{tabular}

Float and Sink Analysis of Fine Spiral Middling Product

+ No.70 mesh

\begin{tabular}{lrrrr}
\hline \multirow{2}{*}{ Specific Gravity Interval } & \multicolumn{3}{c}{ Direct } & \multicolumn{3}{c}{ Cumulative Float } \\
\cline { 2 - 5 } & Weight $\%$ & \% Ash & Weight \% & \% Ash \\
\hline$<1.30$ & 57.81 & 8.04 & 57.81 & 8.04 \\
$1.30-1.40$ & 9.83 & 6.93 & 67.64 & 7.88 \\
$1.40-1.50$ & 10.68 & 13.68 & 78.32 & 8.67 \\
$1.50-1.60$ & 16.09 & 19.58 & 94.42 & 10.53 \\
$1.60-1.70$ & 5.58 & 25.42 & 100.00 & 11.36 \\
$>1.70$ & 0.00 & 0.00 & 100.00 & 11.36 \\
& 100.00 & 11.36 & & \\
\hline
\end{tabular}


Float and Sink Analysis of Fine Spiral Middling Product

- No.70 + No.100 mesh

\begin{tabular}{lrrrr}
\hline \multirow{2}{*}{$\begin{array}{c}\text { Specific Gravity } \\
\text { Interval }\end{array}$} & \multicolumn{2}{c}{ Direct } & \multicolumn{3}{c}{ Cumulative Float } \\
\cline { 2 - 5 }$<1.30$ & 51.48 & 5.35 & 51.48 & 5.35 \\
$1.30-1.40$ & 14.49 & 4.79 & 65.97 & 5.23 \\
$1.40-1.50$ & 12.16 & 8.29 & 78.13 & 5.70 \\
$1.50-1.60$ & 13.54 & 11.87 & 91.67 & 6.61 \\
$1.60-1.70$ & 3.75 & 14.25 & 95.42 & 6.91 \\
$>1.70$ & 4.58 & 26.70 & 100.00 & 7.82 \\
& 100.00 & 7.82 & & \\
\hline
\end{tabular}

Float and Sink Analysis of Fine Spiral Middling Product

- No.100+ No.200 mesh

\begin{tabular}{lrrrr}
\hline \multirow{2}{*}{$\begin{array}{c}\text { Specific Gravity } \\
\text { Interval }\end{array}$} & \multicolumn{2}{c}{ Direct } & \multicolumn{2}{c}{ Cumulative Float } \\
\cline { 2 - 5 }$<1.30$ & 50.15 & 5.36 & 50.15 & 5.36 \\
$1.30-1.40$ & 10.75 & 4.67 & 60.90 & 5.24 \\
$1.40-1.50$ & 16.82 & 6.57 & 77.71 & 5.53 \\
$1.50-1.60$ & 13.99 & 9.06 & 91.70 & 6.07 \\
$1.60-1.70$ & 5.01 & 10.71 & 96.71 & 6.31 \\
$>1.70$ & 3.29 & 13.98 & 100.00 & 6.56 \\
\hline
\end{tabular}


Float and Sink Analysis of Fine Spiral Middling Product

- No.200+ No.325 mesh

\begin{tabular}{lrrrr}
\hline \multirow{2}{*}{$\begin{array}{c}\text { Specific Gravity } \\
\text { Interval }\end{array}$} & \multicolumn{2}{c}{ Direct } & \multicolumn{3}{c}{ Cumulative Float } \\
\cline { 2 - 5 }$<1.30$ & 15.99 & 8.43 & 15.99 & 8.43 \\
$1.30-1.40$ & 11.05 & 5.28 & 27.04 & 7.14 \\
$1.40-1.50$ & 17.61 & 5.72 & 44.64 & 6.58 \\
$1.50-1.60$ & 18.83 & 8.08 & 63.47 & 7.03 \\
$1.60-1.70$ & 19.61 & 9.67 & 83.08 & 7.65 \\
$>1.70$ & 16.92 & 14.64 & 100.00 & 8.83 \\
& 100.00 & 8.83 & & \\
\hline
\end{tabular}

Float and Sink Analysis of Fine Spiral Middling Product

- No.325 mesh

\begin{tabular}{lrrrr}
\hline \multirow{2}{*}{$\begin{array}{c}\text { Specific Gravity } \\
\text { Interval }\end{array}$} & \multicolumn{2}{c}{ Direct } & \multicolumn{2}{c}{ Cumulative Float } \\
\cline { 2 - 5 }$<1.30$ & 45.06 & 27.30 & 45.06 & 27.30 \\
$1.30-1.40$ & 3.00 & 8.57 & 48.06 & 26.13 \\
$1.40-1.50$ & 4.97 & 10.10 & 53.03 & 24.63 \\
$1.50-1.60$ & 9.44 & 11.44 & 62.47 & 22.64 \\
$1.60-1.70$ & 3.77 & 10.73 & 66.24 & 21.96 \\
$>1.70$ & 33.76 & 36.56 & 100.00 & 26.89 \\
& 100.00 & 26.89 & & \\
\hline
\end{tabular}


Float and Sink Analysis of Fine Spiral Refuse Product

+ No.70 mesh

\begin{tabular}{lrrrr}
\hline \multirow{2}{*}{ Specific Gravity Interval } & \multicolumn{2}{c}{ Direct } & \multicolumn{2}{c}{ Cumulative Float } \\
\cline { 2 - 5 } & Weight $\%$ & \% Ash & Weight \% & \% Ash \\
\hline$<1.30$ & 66.93 & 7.28 & 66.93 & 7.28 \\
$1.30-1.40$ & 10.34 & 5.86 & 77.27 & 7.09 \\
$1.40-1.50$ & 8.78 & 5.68 & 86.04 & 6.95 \\
$1.50-1.60$ & 10.33 & 10.93 & 96.38 & 7.37 \\
$1.60-1.70$ & 3.62 & 17.92 & 100.00 & 7.76 \\
$>1.70$ & 0.00 & 0.00 & 100.00 & 7.76 \\
& 100.00 & 7.76 & & \\
\hline
\end{tabular}

Float and Sink Analysis of Fine Spiral Refuse Product

- No.70+ No.100 mesh

\begin{tabular}{lrrrr}
\hline \multirow{2}{*}{$\begin{array}{c}\text { Specific Gravity } \\
\text { Interval }\end{array}$} & \multicolumn{2}{c}{ Direct } & \multicolumn{3}{c}{ Cumulative Float } \\
\cline { 2 - 5 }$<1.30$ & Weight $\%$ & $\%$ Ash & Weight \% & $\%$ Ash \\
\hline $1.30-1.40$ & 10.36 & 4.51 & 54.39 & 5.70 \\
$1.40-1.50$ & 9.66 & 4.39 & 64.75 & 5.51 \\
$1.50-1.60$ & 10.48 & 8.06 & 74.40 & 5.36 \\
$1.60-1.70$ & 2.33 & 13.65 & 84.89 & 5.70 \\
$>1.70$ & 12.78 & 35.00 & 87.22 & 5.91 \\
& 100.00 & 9.63 & 100.00 & 9.63 \\
\hline
\end{tabular}


Float and Sink Analysis of Fine Spiral Refuse Product

- No. $100+$ No. 200 mesh

\begin{tabular}{lrrrr}
\hline \multirow{2}{*}{$\begin{array}{c}\text { Specific Gravity } \\
\text { Interval }\end{array}$} & \multicolumn{2}{c}{ Direct } & \multicolumn{3}{c}{ Cumulative Float } \\
\cline { 2 - 5 }$<1.30$ & Weight \% & \% Ash & Weight \% & \% Ash \\
\hline $1.30-1.40$ & 57.84 & 5.69 & 57.84 & 5.69 \\
$1.40-1.50$ & 9.94 & 4.27 & 67.77 & 5.48 \\
$1.50-1.60$ & 15.41 & 4.25 & 83.18 & 5.25 \\
$1.60-1.70$ & 9.93 & 6.79 & 93.11 & 5.42 \\
$>1.70$ & 2.38 & 11.23 & 95.49 & 5.56 \\
& 4.51 & 29.54 & 100.00 & 6.64 \\
\hline
\end{tabular}

Float and Sink Analysis of Fine Spiral Refuse Product

- No. $200+$ No. 325 mesh

\begin{tabular}{lrrrr}
\hline \multirow{2}{*}{$\begin{array}{c}\text { Specific Gravity } \\
\text { Interval }\end{array}$} & \multicolumn{2}{c}{ Direct } & \multicolumn{3}{c}{ Cumulative Float } \\
\cline { 2 - 5 }$<1.30$ & Weight \% & \% Ash & Weight \% & \% Ash \\
\hline $1.30-1.40$ & 29.57 & 9.25 & 29.57 & 9.25 \\
$1.40-1.50$ & 9.63 & 4.77 & 39.20 & 8.15 \\
$1.50-1.60$ & 23.04 & 4.59 & 62.24 & 6.83 \\
$1.60-1.70$ & 16.04 & 6.03 & 78.28 & 6.67 \\
$>1.70$ & 6.53 & 9.91 & 84.81 & 6.92 \\
& 15.19 & 30.75 & 100.00 & 10.54 \\
& 100.00 & 10.54 & & \\
\hline
\end{tabular}


Float and Sink Analysis of Fine Spiral Refuse Product

- No.325 mesh

\begin{tabular}{lrrrr}
\hline \multirow{2}{*}{$\begin{array}{c}\text { Specific Gravity } \\
\text { Interval }\end{array}$} & \multicolumn{2}{c}{ Direct } & \multicolumn{3}{c}{ Cumulative Float } \\
\cline { 2 - 5 } \multicolumn{1}{c}{ Weight \% } & \% Ash & Weight \% & \% Ash \\
\hline 1.30 & 12.02 & 28.67 & 12.02 & 28.67 \\
$1.30-1.40$ & 1.40 & 17.61 & 13.41 & 27.52 \\
$1.40-1.50$ & 3.87 & 17.25 & 17.28 & 25.22 \\
$1.50-1.60$ & 7.39 & 13.00 & 24.67 & 21.56 \\
$1.60-1.70$ & 2.09 & 10.66 & 26.76 & 20.71 \\
$>1.70$ & 73.24 & 24.64 & 100.00 & 23.59 \\
& 100.00 & 23.59 & & \\
\hline
\end{tabular}

Float and Sink Analysis of Coarse Spiral Clean Coal

+ No.16 mesh

\begin{tabular}{lrrrr}
\hline \multirow{2}{*}{$\begin{array}{c}\text { Specific Gravity } \\
\text { Interval }\end{array}$} & \multicolumn{2}{c}{ Direct } & \multicolumn{3}{c}{ Cumulative Float } \\
\cline { 2 - 5 }$<1.30$ & Weight \% & \% Ash & Weight \% & \% Ash \\
\hline $1.30-1.40$ & 89.05 & 5.58 & 89.05 & 5.58 \\
$1.40-1.50$ & 10.95 & 7.44 & 100.00 & 5.78 \\
$1.50-1.60$ & 0.00 & 0.00 & 100.00 & 5.78 \\
$1.60-1.70$ & 0.00 & 0.00 & 100.00 & 5.78 \\
$>1.70$ & 0.00 & 0.00 & 100.00 & 5.78 \\
& 0.00 & 0.00 & 100.00 & 5.78 \\
\hline
\end{tabular}


Float and Sink Analysis of Coarse Spiral Clean Coal

- No.16+ No.40 mesh

\begin{tabular}{lrrrr}
\hline \multirow{2}{*}{$\begin{array}{c}\text { Specific Gravity } \\
\text { Interval }\end{array}$} & \multicolumn{2}{c}{ Direct } & \multicolumn{2}{c}{ Cumulative Float } \\
\cline { 2 - 5 }$<1.30$ & Weight $\%$ & \% Ash & Weight $\%$ & $\%$ Ash \\
\hline $1.30-1.40$ & 16.19 & 6.81 & 75.27 & 3.98 \\
$1.40-1.50$ & 3.91 & 16.48 & 91.46 & 4.48 \\
$1.50-1.60$ & 1.68 & 25.57 & 95.37 & 4.97 \\
$1.60-1.70$ & 1.07 & 37.11 & 97.05 & 5.33 \\
$>1.70$ & 1.88 & 55.44 & 98.12 & 5.68 \\
& 100.00 & 6.61 & 100.00 & 6.61 \\
\hline
\end{tabular}

Float and Sink Analysis of Coarse Spiral Clean Coal

- No.40+ No.70 mesh

\begin{tabular}{lrrrr}
\hline \multirow{2}{*}{$\begin{array}{c}\text { Specific Gravity } \\
\text { Interval }\end{array}$} & \multicolumn{2}{c}{ Direct } & \multicolumn{2}{c}{ Cumulative Float } \\
\cline { 2 - 5 }$<1.30$ & Weight $\%$ & $\%$ Ash & Weight \% & $\%$ Ash \\
\hline $1.30-1.40$ & 31.69 & 5.72 & 60.46 & 3.50 \\
$1.40-1.50$ & 4.46 & 14.39 & 92.14 & 4.26 \\
$1.50-1.60$ & 1.49 & 22.95 & 96.60 & 4.73 \\
$1.60-1.70$ & 0.88 & 34.00 & 98.09 & 5.01 \\
$>1.70$ & 1.03 & 49.84 & 98.97 & 5.27 \\
& 100.00 & 5.72 & 100.00 & 5.72 \\
\hline
\end{tabular}


Float and Sink Analysis of Coarse Spiral Clean Coal

- No.70+ No. 100 mesh

\begin{tabular}{lrrrr}
\hline \multirow{2}{*}{$\begin{array}{c}\text { Specific Gravity } \\
\text { Interval }\end{array}$} & \multicolumn{2}{c}{ Direct } & \multicolumn{2}{c}{ Cumulative Float } \\
\cline { 2 - 5 }$<1.30$ & Weight $\%$ & \% Ash & Weight \% & $\%$ Ash \\
\hline $1.30-1.40$ & 34.14 & 3.47 & 53.14 & 3.47 \\
$1.40-1.50$ & 6.84 & 13.09 & 87.17 & 4.09 \\
$1.50-1.60$ & 2.39 & 20.65 & 94.00 & 4.74 \\
$1.60-1.70$ & 1.42 & 32.07 & 96.39 & 5.14 \\
$>1.70$ & 2.19 & 53.94 & 97.81 & 5.53 \\
& 100.00 & 6.59 & 100.00 & 6.59 \\
\hline
\end{tabular}

Float and Sink Analysis of Coarse Spiral Clean Coal

- No.100 mesh

\begin{tabular}{lrrrr}
\hline \multirow{2}{*}{$\begin{array}{c}\text { Specific Gravity } \\
\text { Interval }\end{array}$} & \multicolumn{2}{c}{ Direct } & \multicolumn{2}{c}{ Cumulative Float } \\
\cline { 2 - 5 }$<1.30$ & Weight $\%$ & \% Ash & Weight \% & $\%$ Ash \\
\hline $1.30-1.40$ & 30.70 & 8.13 & 40.70 & 8.13 \\
$1.40-1.50$ & 8.69 & 15.33 & 75.87 & 8.43 \\
$1.50-1.60$ & 3.43 & 21.57 & 84.56 & 9.14 \\
$1.60-1.70$ & 1.69 & 30.25 & 87.99 & 9.62 \\
$>1.70$ & 10.33 & 59.97 & 89.67 & 10.01 \\
& 100.00 & 15.17 & 100.00 & 15.17 \\
\hline
\end{tabular}


Float and Sink Analysis of Coarse Spiral Middling Product

+ No.16 mesh

\begin{tabular}{lrrrr}
\hline \multirow{2}{*}{$\begin{array}{c}\text { Specific Gravity } \\
\text { Interval }\end{array}$} & \multicolumn{2}{c}{ Direct } & \multicolumn{2}{c}{ Cumulative Float } \\
\cline { 2 - 5 }$<1.30$ & 0.00 & 0.00 & 0.00 & 0.00 \\
$1.30-1.40$ & 0.00 & 0.00 & 0.00 & 0.00 \\
$1.40-1.50$ & 0.00 & 0.00 & 0.00 & 0.00 \\
$1.50-1.60$ & 0.00 & 0.00 & 0.00 & 0.00 \\
$1.60-1.70$ & 0.00 & 0.00 & 0.00 & 0.00 \\
$>1.70$ & 100.00 & 76.39 & 100.00 & 76.39 \\
& 100.00 & 76.39 & & \\
\hline
\end{tabular}

Float and Sink Analysis of Coarse Spiral Middling Product

- No.16+ No.40 mesh

\begin{tabular}{lrrrr}
\hline \multirow{2}{*}{$\begin{array}{c}\text { Specific Gravity } \\
\text { Interval }\end{array}$} & \multicolumn{2}{c}{ Direct } & \multicolumn{3}{c}{ Cumulative Float } \\
\cline { 2 - 5 }$<1.30$ & 81.91 & 7.25 & 81.91 & 7.25 \\
$1.30-1.40$ & 6.65 & 16.64 & 88.56 & 7.95 \\
$1.40-1.50$ & 0.44 & 13.55 & 89.00 & 7.98 \\
$1.50-1.60$ & 7.33 & 22.23 & 96.34 & 9.07 \\
$1.60-1.70$ & 3.66 & 24.75 & 100.00 & 9.64 \\
$>1.70$ & 0.00 & 62.86 & 100.00 & 9.64 \\
& 100.00 & 9.64 & & \\
\hline
\end{tabular}


Float and Sink Analysis of Coarse Spiral Middling Product

- No.40+ No.70 mesh

\begin{tabular}{|c|c|c|c|c|}
\hline \multirow{2}{*}{$\begin{array}{l}\text { Specific Gravity } \\
\text { Interval }\end{array}$} & \multicolumn{2}{|l|}{ Direct } & \multicolumn{2}{|c|}{ Cumulative Float } \\
\hline & Weight $\%$ & $\%$ Ash & Weight $\%$ & $\%$ Ash \\
\hline$<1.30$ & 70.04 & 6.24 & 70.04 & 6.24 \\
\hline $1.30-1.40$ & 12.43 & 10.38 & 82.47 & 6.86 \\
\hline $1.40-1.50$ & 0.42 & 10.71 & 82.89 & 6.88 \\
\hline $1.50-1.60$ & 14.04 & 16.09 & 96.94 & 8.22 \\
\hline $1.60-1.70$ & 3.06 & 29.55 & 100.00 & 8.87 \\
\hline \multirow[t]{2}{*}{$>1.70$} & 0.00 & 55.36 & 100.00 & 8.87 \\
\hline & 100.00 & 8.87 & & \\
\hline
\end{tabular}

Float and Sink Analysis of Coarse Spiral Middling Product

- No.70+ No. 100 mesh

\begin{tabular}{lrrrr}
\hline \multirow{2}{*}{$\begin{array}{c}\text { Specific Gravity } \\
\text { Interval }\end{array}$} & \multicolumn{2}{c}{ Direct } & \multicolumn{3}{c}{ Cumulative Float } \\
\cline { 2 - 5 }$<1.30$ & Weight \% & \% Ash & Weight \% & \% Ash \\
\hline $1.30-1.40$ & 11.85 & 8.25 & 60.35 & 7.19 \\
$1.40-1.50$ & 2.44 & 11.46 & 72.20 & 7.36 \\
$1.50-1.60$ & 21.28 & 13.13 & 95.64 & 7.50 \\
$1.60-1.70$ & 4.08 & 25.04 & 100.00 & 9.75 \\
$>1.70$ & 0.00 & 56.63 & 100.00 & 9.41 \\
& 100.00 & 9.41 & & \\
\hline
\end{tabular}


Float and Sink Analysis of Coarse Spiral Middling Product

- No.100 mesh

\begin{tabular}{lrrrr}
\hline \multirow{2}{*}{$\begin{array}{c}\text { Specific Gravity } \\
\text { Interval }\end{array}$} & \multicolumn{2}{c}{ Direct } & \multicolumn{2}{c}{ Cumulative Float } \\
\cline { 2 - 5 }$<1.30$ & Weight $\%$ & $\%$ Ash & Weight $\%$ & $\%$ Ash \\
\hline $1.30-1.40$ & 16.12 & 10.37 & 68.17 & 8.03 \\
$1.40-1.50$ & 0.62 & 11.97 & 84.29 & 10.37 \\
$1.50-1.60$ & 12.62 & 13.27 & 84.91 & 11.97 \\
$1.60-1.70$ & 2.47 & 25.07 & 97.53 & 13.27 \\
$>1.70$ & 0.00 & 72.29 & 100.00 & 25.07 \\
& 100.00 & 9.51 & 100.00 & 9.51 \\
\hline
\end{tabular}

Float and Sink Analysis of Coarse Spiral Refuse Product

+ No.16 mesh

\begin{tabular}{lrrrr}
\hline \multirow{2}{*}{$\begin{array}{c}\text { Specific Gravity } \\
\text { Interval }\end{array}$} & \multicolumn{2}{c}{ Direct } & \multicolumn{3}{c}{ Cumulative Float } \\
\cline { 2 - 5 }$<1.30$ & 0.00 & 0.00 & 0.00 & 0.00 \\
$1.30-1.40$ & 0.00 & 0.00 & 0.00 & 0.00 \\
$1.40-1.50$ & 0.00 & 0.00 & 0.00 & 0.00 \\
$1.50-1.60$ & 0.00 & 0.00 & 0.00 & 0.00 \\
$1.60-1.70$ & 0.00 & 0.00 & 0.00 & 0.00 \\
$>1.70$ & 0.00 & 0.00 & 0.00 & 0.00 \\
& 100.00 & 0.00 & & \\
\hline
\end{tabular}


Float and Sink Analysis of Coarse Spiral Refuse Product

- No.16+ No.40 mesh

\begin{tabular}{lrrrr}
\hline \multirow{2}{*}{$\begin{array}{c}\text { Specific Gravity } \\
\text { Interval }\end{array}$} & \multicolumn{2}{c}{ Direct } & \multicolumn{2}{c}{ Cumulative Float } \\
\cline { 2 - 5 }$<1.30$ & Weight $\%$ & \% Ash & Weight \% & \% Ash \\
\hline $1.30-1.40$ & 33.25 & 9.62 & 55.59 & 6.77 \\
$1.40-1.50$ & 6.13 & 13.52 & 88.84 & 7.84 \\
$1.50-1.60$ & 2.24 & 26.13 & 94.97 & 8.20 \\
$1.60-1.70$ & 2.79 & 29.29 & 97.21 & 8.62 \\
$>1.70$ & 0.00 & 0.00 & 100.00 & 9.19 \\
& 100.00 & 9.19 & 100.00 & 9.19 \\
\hline
\end{tabular}

Float and Sink Analysis of Coarse Spiral Refuse Product

- No.40+ No.70 mesh

\begin{tabular}{lrrrr}
\hline \multirow{2}{*}{$\begin{array}{c}\text { Specific Gravity } \\
\text { Interval }\end{array}$} & \multicolumn{2}{c}{ Direct } & \multicolumn{3}{c}{ Cumulative Float } \\
\cline { 2 - 5 }$<1.30$ & 36.57 & 7.75 & 36.57 & 7.75 \\
$1.30-1.40$ & 44.56 & 8.84 & 81.13 & 8.35 \\
$1.40-1.50$ & 9.62 & 11.07 & 90.75 & 8.64 \\
$1.50-1.60$ & 1.87 & 22.53 & 92.62 & 8.92 \\
$1.60-1.70$ & 7.38 & 17.90 & 100.00 & 9.58 \\
$>1.70$ & 0.00 & 0.00 & 100.00 & 9.58 \\
& 100.00 & 9.58 & & \\
\hline
\end{tabular}


Float and Sink Analysis of Coarse Spiral Refuse Product

- No.70+ No. 100 mesh

\begin{tabular}{lrrrr}
\hline \multirow{2}{*}{$\begin{array}{c}\text { Specific Gravity } \\
\text { Interval }\end{array}$} & \multicolumn{2}{c}{ Direct } & \multicolumn{2}{c}{ Cumulative Float } \\
\cline { 2 - 5 }$<1.30$ & \multicolumn{1}{c}{ Weight $\%$} & \% Ash & Weight $\%$ & $\%$ Ash \\
\hline $1.30-1.40$ & 46.18 & 11.44 & 8.99 & 9.85 \\
$1.40-1.50$ & 20.42 & 10.90 & 55.17 & 11.18 \\
$1.50-1.60$ & 2.16 & 11.76 & 75.60 & 11.10 \\
$1.60-1.70$ & 22.24 & 23.21 & 77.76 & 11.12 \\
$>1.70$ & 0.00 & 0.00 & 100.00 & 13.81 \\
& 100.00 & 13.81 & 100.00 & 13.81 \\
\hline
\end{tabular}

Float and Sink Analysis of Coarse Spiral Refuse Product

- No.100 mesh

\begin{tabular}{lrrrr}
\hline \multirow{2}{*}{$\begin{array}{c}\text { Specific Gravity } \\
\text { Interval }\end{array}$} & \multicolumn{2}{c}{ Direct } & \multicolumn{2}{c}{ Cumulative Float } \\
\cline { 2 - 5 }$<1.30$ & Weight $\%$ & \% Ash & Weight \% & \% Ash \\
\hline $1.30-1.40$ & 30.11 & 14.23 & 40.11 & 14.23 \\
$1.40-1.50$ & 13.44 & 10.90 & 70.50 & 11.44 \\
$1.50-1.60$ & 1.42 & 11.76 & 83.94 & 10.90 \\
$1.60-1.70$ & 14.64 & 23.21 & 85.36 & 11.76 \\
$>1.70$ & 0.00 & 0.00 & 100.00 & 23.21 \\
& 100.00 & 14.21 & 100.00 & 14.21 \\
\hline
\end{tabular}

